\title{
Synthesizing long-term sea level rise projections - the MAGICC sea level model v2.0
}

\author{
Alexander Nauels ${ }^{1,2}$, Malte Meinshausen ${ }^{1,2,3}$, Matthias Mengel ${ }^{3}$, Katja Lorbacher ${ }^{1}$, and Tom M. L. Wigley ${ }^{4,5}$ \\ ${ }^{1}$ Australian-German Climate and Energy College, The University of Melbourne, Parkville 3010, Victoria, Australia \\ ${ }^{2}$ Department of Earth Sciences, The University of Melbourne, Parkville 3010, Victoria, Australia \\ ${ }^{3}$ Potsdam Institute for Climate Impact Research (PIK), Telegrafenberg, 14473 Potsdam, Germany \\ ${ }^{4}$ The Environment Institute and School of Biological Sciences, The University of Adelaide, Adelaide, SA 5005, Australia \\ ${ }^{5}$ Climate and Global Dynamics Division, National Center for Atmospheric Research, Boulder, CO 80307-3000, USA
}

Correspondence to: Alexander Nauels (alexander.nauels@ climate-energy-college.org)

Received: 31 August 2016 - Discussion started: 5 October 2016

Revised: 21 June 2017 - Accepted: 22 June 2017 - Published: 30 June 2017

\begin{abstract}
Sea level rise (SLR) is one of the major impacts of global warming; it will threaten coastal populations, infrastructure, and ecosystems around the globe in coming centuries. Well-constrained sea level projections are needed to estimate future losses from SLR and benefits of climate protection and adaptation. Process-based models that are designed to resolve the underlying physics of individual sea level drivers form the basis for state-of-the-art sea level projections. However, associated computational costs allow for only a small number of simulations based on selected scenarios that often vary for different sea level components. This approach does not sufficiently support sea level impact science and climate policy analysis, which require a sea level projection methodology that is flexible with regard to the climate scenario yet comprehensive and bound by the physical constraints provided by process-based models. To fill this gap, we present a sea level model that emulates global-mean long-term process-based model projections for all major sea level components. Thermal expansion estimates are calculated with the hemispheric upwellingdiffusion ocean component of the simple carbon-cycle climate model MAGICC, which has been updated and calibrated against CMIP5 ocean temperature profiles and thermal expansion data. Global glacier contributions are estimated based on a parameterization constrained by transient and equilibrium process-based projections. Sea level contribution estimates for Greenland and Antarctic ice sheets are derived from surface mass balance and solid ice discharge parameterizations reproducing current output from ice-sheet
\end{abstract}

models. The land water storage component replicates recent hydrological modeling results. For 2100 , we project 0.35 to $0.56 \mathrm{~m}$ (66\% range) total SLR based on the RCP2.6 scenario, 0.45 to $0.67 \mathrm{~m}$ for RCP4.5, 0.46 to $0.71 \mathrm{~m}$ for RCP6.0, and 0.65 to $0.97 \mathrm{~m}$ for RCP8.5. These projections lie within the range of the latest IPCC SLR estimates. SLR projections for 2300 yield median responses of $1.02 \mathrm{~m}$ for RCP2.6, $1.76 \mathrm{~m}$ for RCP4.5, $2.38 \mathrm{~m}$ for RCP6.0, and $4.73 \mathrm{~m}$ for RCP8.5. The MAGICC sea level model provides a flexible and efficient platform for the analysis of major scenario, model, and climate uncertainties underlying long-term SLR projections. It can be used as a tool to directly investigate the SLR implications of different mitigation pathways and may also serve as input for regional SLR assessments via component-wise sea level pattern scaling.

\section{Introduction}

Global sea level has increased by around $0.2 \mathrm{~m}$ since the beginning of the 20th century and will continue to rise during the 21st century and far beyond (Church and White, 2011; Church et al., 2013a). This will have wide-ranging impacts for coastal regions around the globe and therefore requires careful monitoring. The total sea level signal is the sum of several individual sea level components, the main ones being thermal expansion, global glacier melt, Greenland and Antarctic ice-sheet mass loss, and land water storage changes (Church et al., 2013a). Over the coming centuries, the mag- 
nitude of total sea level rise (SLR) will strongly depend on the amount of anthropogenic greenhouse gases (GHGs) emitted to the atmosphere during the 21 st century and the corresponding physical responses of the major SLR drivers (Horton et al., 2014). Future GHG emissions are therefore a main uncertainty source when trying to project SLR trajectories. SLR uncertainties are further increased by structural differences of the underlying process-based models for the individual SLR contributions and limited process understanding, like the behavior of polar ice shelves in a warming world (Nicholls and Cazenave, 2010). To assess major parts of these scenario and model uncertainties, we extend the widely used simple carbon-cycle climate model MAGICC (Meinshausen et al., 2011a, 2009; Wigley et al., 2009; Wigley and Raper, 2001) to comprehensively model global SLR. This MAGICC sea level model has been designed to emulate the behavior of process-based sea level projections presented in the fifth IPCC Assessment Report (Church et al., 2013a), with thorough calibrations for each major sea level component. It is intended to serve as an efficient and flexible tool for the assessment of multi-centennial global SLR. In the following section, we motivate and explain the key concepts underlying the MAGICC sea level model. Section 2 covers the detailed model description and Sect. 3 provides key results. In Sect. 4, we discuss the capabilities of the presented sea level emulator and shine a first light on potential applications.

\section{Motivation}

Future sea level is modeled with varying degrees of complexity. Process-based modeling represents the physically most comprehensive but also computationally most expensive approach to project SLR. It is based on AtmosphereOcean General Circulation Models (AOGCMs) and specialized glacier, ice-sheet and groundwater models that dynamically simulate sea level changes resulting from natural and anthropogenic forcings. The main sea level output from AOGCMs is the thermosteric ocean response, mostly diagnosed with post-simulation adjustments to compensate Boussinesq approximation effects (Griffies and Greatbatch, 2012). Process-based glacier and ice-sheet models are generally run separately or "offline" and receive important boundary conditions either from observational data, AOGCMs, or regional climate model input (Rae et al., 2012; Pattyn et al., 2012). Due to the complexity of the physical processes required to capture the dynamical response of each individual component, this SLR modeling approach is not feasible for efficient multi-centennial and multi-scenario research designs. It is mainly used to improve our physical understanding of the individual SLR components. The need for more efficient tools to project long-term SLR has led to the development of alternative approaches.

In the 1980s, first semi-empirical models (SEMs), which estimate global sea level changes based on the evolution of global-mean temperature, were introduced together with early approaches to model thermal expansion based on simplified ocean processes (Gornitz et al., 1982). Generally, SEMs establish statistical relationships between observed/reconstructed global-mean temperature or radiative forcing changes and observed/reconstructed global-mean sea level changes. Assuming that such relationships do not change in the future, they are used to estimate future SLR from projected global temperature/forcing changes (Rahmstorf, 2007; Vermeer and Rahmstorf, 2009; Jevrejeva et al., 2010; Kopp et al., 2016). Therefore, these SEMs do not calculate sea level by resolving the underlying physical processes. This approach generated considerable scientific debate and was not included in latest IPCC estimates (Orlic and Pasaric, 2013; Storch et al., 2008; Church et al., 2013a). The computational efficiency of this method, however, made it attractive to applied research questions, like investigating the global-mean SLR response for different climate targets (Schaeffer et al., 2012). Recently, this method has been developed further and was applied to individual sea level components (Mengel et al., 2016). SLR projections are also provided based on expert elicitations (Horton et al., 2014). Furthermore, sea level expert judgments have been combined with statistical models synthesizing sea level projections for individual components (Kopp et al., 2014). Other studies have used an extended suite of methods, analyzing paleoclimatic archives, modeling parts of the SLR response with a reduced complexity model, and deriving future projections for land-ice contribution-based semi-empirical considerations (Clark et al., 2016). The growing efforts in the sea level modeling community to provide fully transparent and freely available model code are reflected by the recent introduction of a transparent, simple model framework to estimate regional sea levels (Wong et al., 2017). Previous MAGICC versions also provided SLR estimates based on simplified parameterizations for selected components (Wigley and Raper, 1987, 1992, 2005; Wigley, 1995).

Here, we adopt an approach of deriving a total sea level response by emulating existing process-based projections for individual sea level components (Perrette et al., 2013; Schleussner et al., 2016). Future sea level dynamics is synthesized by calibrating simplified parameterizations to the selected complex model projections for all major sea level contributions. Progress in the understanding of individual sea level processes and the availability of revised future sea level contributions require sea level emulators to be updated regularly. With this study, we are able to complement the existing sea level projection emulators with a platform based on a comprehensive set of individual sea level components that allows for projections consistent with IPCC AR5 estimates. The MAGICC sea level model represents the first efficient sea level emulator that dynamically calculates thermal expansion with a hemispheric upwelling-diffusion model based on full hemispheric ocean temperature profiles calibrated with data from phase 5 of the Coupled Model Intercompari- 
son Project (CMIP5) (Taylor et al., 2012). It mimics processbased sea level responses for the seven main sea level components with thoroughly calibrated parameterizations that extend global sea level projections to 2300. Integration of the sea level model into MAGICC ensures a consistent treatment of future SLR and its uncertainties along the full chain from emissions to atmospheric composition, to temperature to sea level. With the option to run large ensembles in a probabilistic setup, the MAGICC sea level model allows one to explore the scenario and model uncertainty space and directly investigate SLR responses associated with mitigation pathways that are not covered by the standard RCP scenarios (Moss et al., 2010). In addition, the MAGICC global SLR projections could be used for calculating regional SLR information by using them as input for pattern scaling approaches (Perrette et al., 2013).

\section{Model description}

The MAGICC sea level emulator (Fig. 1) has been developed as an extension to the widely used MAGICC model version 6 (Meinshausen et al., 2011a, b). The MAGICC ocean model has been revised and calibrated with available CMIP5 ocean temperature and thermal expansion data. The updated MAGICC ocean provides the basis for our thermal expansion parameterization based on Lorbacher et al. (2015). Parameterizations for global glacier, Greenland surface mass balance (SMB), Antarctic SMB, and Greenland solid ice discharge (SID) have been calibrated against selected process-based projections for the corresponding SLR components. The linear response function approach for the Antarctic SID component presented in Levermann et al. (2014) was adapted to satisfy MAGICC model specifications. In addition, we have implemented the option to include land water SLR contribution estimates based on Wada et al. (2012, 2016), with an extension until 2300.

\subsection{MAGICC ocean model update and thermal expansion}

MAGICC is based on a hemispheric upwelling-diffusion entrainment ocean model with depth-dependent areas for each of its 50 ocean layers (Meinshausen et al., 2011a). In this study, we provide a first series of updates for MAGICC version 7, which will be consistent with the ensemble output of CMIP5 (Taylor et al., 2012). The upwelling velocity is variable in MAGICC and the model conserves the upwelling mass flux through layer-specific entrainment which is proportional to the area decrease from the top to the bottom of each layer. To avoid overestimation of ocean heat uptake for higher warming scenarios, the ocean routine includes a warming-dependent vertical diffusivity term which leads to reduced heat uptake efficiency for higher warming (Meinshausen et al., 2011a). In MAGICC6, the air temperature in- creases were assumed proportional to the mixed-layer ocean temperatures. A proportionality constant $\alpha$ (default value: 1.25 ) is used in earlier versions of MAGICC to account for diminishing sea-ice extent in the Arctic, exposing a larger area of the (relatively warm) surface ocean waters as warming progresses with time. Here, we replace this constant factor by a term that takes into account the fact that this amplifying effect will itself diminish as the Arctic sea-ice retreat is bound by the limit of a sea-ice-free ocean in summer. The chosen functional form initially assumes a simple linear amplification (as in MAGICC6), and then progresses asymptotically towards a constant offset between the surface air temperature and top ocean-layer warming. This new exponential adjustment term relates hemispheric air temperature change $\Delta T_{x \mathrm{~A}}$ to hemispheric mixed-layer ocean temperature change $\Delta T_{x \mathrm{O}, 1}$ as follows:

$\Delta T_{x \mathrm{~A}}=\Delta T_{x \mathrm{O}, 1}+\eta\left(1-e^{-\gamma \Delta T_{x \mathrm{O}, 1}}\right)$.

For large $\gamma \Delta T_{x \mathrm{O}, 1}$, the new sea-ice adjustment term moves towards a constant offset $\eta$ between surface air temperature warming $\Delta T_{x \mathrm{~A}}$ and mixed-layer ocean warming $\Delta T_{x \mathrm{O}, 1}$. However, the surface air temperature warming initially approximates $\Delta T_{x \mathrm{~A}}=\Delta T_{x \mathrm{O}, 1}(1+\eta \gamma)$ for small $\gamma \Delta T_{x \mathrm{O}, 1}$, with $(1+\eta \gamma)$ representing the old MAGICC6 proportionality coefficient $\alpha$. The sea-ice adjustment parameters $\eta$ and $\gamma$ are optimized together with other selected parameters for every CMIP5 model included in the MAGICC ocean model calibration (see Sect. 2.6). The parameter sets are optimized to represent the depth-dependent potential ocean temperature (thetao) responses from 36 CMIP5 models (see Table 1). The tuned model captures ocean-layer-specific thetao change and related vertical redistribution characteristics of individual CMIP5 models, both indicators for overall ocean heat uptake behavior. Net ocean heat uptake can be robustly translated into thermal expansion (Kuhlbrodt and Gregory, 2012). Therefore, we can define the thermosteric response as the vertical sum of the layer-specific thetao anomalies multiplied by a corresponding thermal expansion coefficient $\alpha$ which is weighted by the specific ocean-layer area. The thermal expansion coefficient $\alpha$ captures all relevant properties of seawater (potential seawater temperature, salinity, and pressure) that determine the corresponding sea level response (Griffies et al., 2014). For MAGICC, a simplified thermal expansion coefficient representation was developed, which is solely based on thetao and pressure (Raper et al., 2001; Wigley et al., 2009). Recently, Lorbacher et al. (2015) have updated this parameterization to match CMIP5 thermal expansion behavior. We build our parameterization on Lorbacher et al. (2015) and calculate the thermal expansion coefficients for every MAGICC depth with the following polynomial of $\theta$ and $p$ :

$\alpha=\left(c_{0}+c_{1} \theta_{0}(12.9635-1.0833 p)-c_{2} \theta_{1}(0.1713\right.$ 


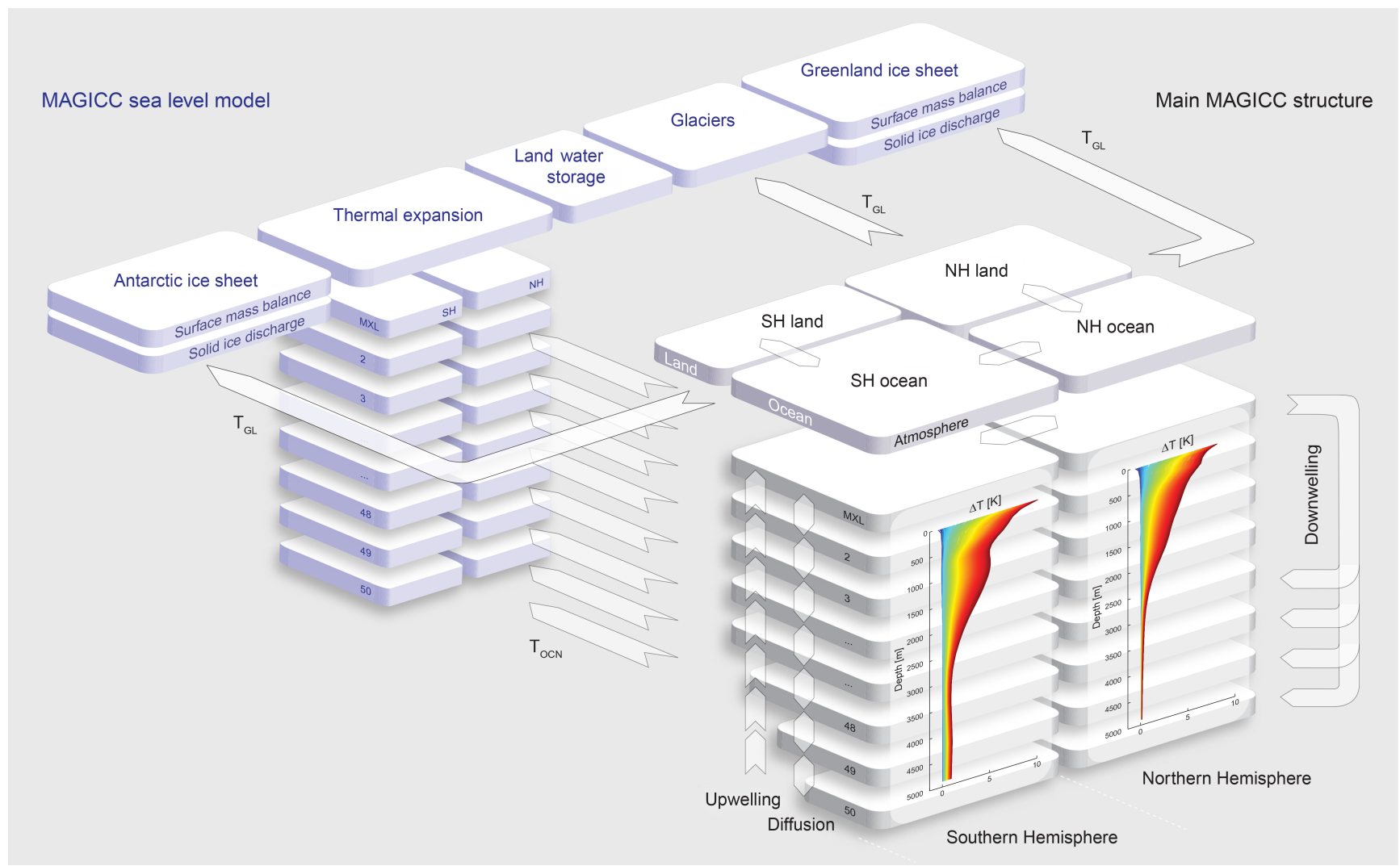

Figure 1. Schematic of the MAGICC sea level model structure and the driving MAGICC hemispheric upwelling-diffusion energy balance core. Heat is transported through the oceans by downwelling and corresponding layer entrainment, upwelling, diffusion, and the exchange between the hemispheres. Ocean mixed layer is denoted MXL, depth-dependent ocean areas are shown by smaller ocean layers towards the ocean bottom. Illustrative potential ocean temperature warming profiles that feed into the layer-dependent thermal expansion module are sketched for both hemispheres. Ocean and air temperature fluxes $\left(T_{\mathrm{OCN}}, T_{\mathrm{GL}}\right)$ relevant for the sea level model as well as other major energy fluxes are shown as arrows. Figure adapted from Meinshausen et al. (2011a).

$$
\begin{aligned}
& -0.019263 p)+c_{3} \theta_{2}(10.41-1.338 p) \\
& \left.+c_{4} p-c_{5} p^{2}\right) 10^{-6} .
\end{aligned}
$$

The hemispheric layer-specific thetao values $\theta_{z}$ are processed for every time step with $\theta_{0}=\theta_{z}, \theta_{1}=\theta_{0}^{2}$, and $\theta_{2}=\frac{\theta_{0}^{3}}{6000}$, assuming a mean maximum ocean depth of $6000 \mathrm{~m}$. The ocean depth profile, $\mathrm{z}$, is translated into the pressure profile $p=$ $0.0098\left(0.1005 z+10.5 \exp \left(\frac{-1.0 z}{3500}-1.0\right)\right.$, with $3500 \mathrm{~m}$ as the mean ocean depth. For each of the 36 MAGICC CMIP5 ocean parameter sets, the corresponding calibration parameters $c_{0-5}$ are taken from Table S2 in Lorbacher et al. (2015). It is the combination of the CMIP5 MAGICC ocean update with the matching thermal expansion parameters that allows us to estimate 36 unique thermal expansion responses based on the selected ensemble of CMIP5 models. Our method does not cover all the spatial heterogeneity effects of thermal expansion that are seen in the three-dimensional CMIP5 fields. Therefore, we apply a model-specific scaling coefficient $\phi$ to the thermosteric estimates for each ocean layer to further improve the fit between the aggregated thermal ex- pansion from the calibrated MAGICC ocean model and the CMIP5 thermosteric SLR (zostoga) estimates (see Sect. 2.6 for more details).

\subsection{Global glaciers}

Mountain glaciers superseded thermal expansion as the biggest single contribution to SLR by the middle of the 20th century (Gregory et al., 2013a). The global mass balance of glaciers likely turned negative in the 19th century, e.g., Leclercq et al. (2011); 20th century glacier mass loss contributed around $0.1 \mathrm{~m}$ of global sea level (Marzeion et al., 2012), with an increasing fraction of the glacier mass loss related to anthropogenic climatic warming, reaching around $70 \%$ in recent years (Marzeion et al., 2014). Analyses of the remaining glacier mass susceptible to melt vary from around $0.35 \mathrm{~m}$ sea level equivalent (SLE) (Grinsted, 2013) to almost $0.5 \mathrm{~m}$ SLE (Marzeion et al., 2012), with both studies including peripheral glaciers of the ice sheets. The latter study is based on a glacier surface mass balance model forced with regional monthly precipitation and temperature 
Table 1. MAGICC ocean model calibration results with optimal sets of ocean and thermal expansion calibration parameters for the available CMIP5 models. Calibration parameters are introduced in Sect. 2.6. Goodness-of-fit (GOF) results are given as weighted residual sum of squares (RSS) divided by the number of calibrated model years (weight potential ocean temperature [K]: 10; weight thermal expansion [mm]: 0.001). The optimal set for the mean response of the calibration data is given at the bottom of the table.

\begin{tabular}{|c|c|c|c|c|c|c|c|c|c|c|}
\hline Model & $K_{z}$ & $\frac{\mathrm{d} K_{z \text { top }}}{\mathrm{d} T}$ & $\eta$ & $\gamma$ & $\beta$ & $w_{0}$ & $\frac{\Delta w_{t}}{w_{t}}$ & $T_{w_{t}}$ & $\phi$ & GOF \\
\hline ACCESS 1.0 & 4.3846 & -1.3441 & 2.4191 & 0.2954 & 0.1997 & 0.0678 & 0.9999 & 1.9021 & 1.1141 & 0.11 \\
\hline ACCESS 1.3 & 0.1792 & -0.0249 & 4.5743 & 0.0806 & 0.0598 & 9.959 & 0.2044 & 3.0533 & 1.1277 & 0.08 \\
\hline BCC-CSM1.1 & 1.3457 & 0.0701 & 2.223 & 0.2245 & 0.2348 & 0.0100 & 0.9506 & 16.417 & 1.0303 & 0.11 \\
\hline BNU-ESM & 1.9336 & -0.4034 & 3.5734 & 0.2422 & 0.6824 & 2.9546 & 0.0010 & 4.5004 & 1.2220 & 0.13 \\
\hline CanESM2 & 0.9065 & 0.2868 & 5.0000 & 0.1132 & 0.1259 & 1.171 & 0.7481 & 8.1589 & 1.0857 & 0.16 \\
\hline CCSM4 & 1.1155 & 0.2327 & 1.6218 & 0.3368 & 0.0132 & 1.2702 & 0.3359 & 1.5202 & 1.0321 & 0.15 \\
\hline CESM1-BGC & 1.1713 & -0.0654 & 3.2018 & 0.1302 & 0.1024 & 9.986 & 0.223 & 3.8928 & 1.0533 & 0.03 \\
\hline CESM1-CAM5 & 0.1000 & 0.8004 & 2.5411 & 0.2834 & 0.0767 & 1.9277 & 0.7618 & 16.873 & 1.0993 & 0.13 \\
\hline CMCC-CESM & 0.4599 & -0.0209 & 1.8620 & 0.2551 & 0.0100 & 10.000 & 0.4610 & 9.4486 & 1.1590 & 0.13 \\
\hline CMCC-CM & 1.4137 & -0.4317 & 1.0552 & 0.9129 & 0.2519 & 1.9925 & 0.9999 & 19.599 & 0.9382 & 0.10 \\
\hline CMCC-CMS & 0.1000 & -0.7989 & 4.9992 & 0.0807 & 0.1531 & 9.9999 & 0.2939 & 4.7474 & 0.9858 & 0.05 \\
\hline CNRM-CM5 & 0.1377 & 0.1547 & 3.2070 & 0.1776 & 0.4134 & 0.5078 & 0.8680 & 1.3343 & 1.0254 & 0.20 \\
\hline CNRM-CM5-2 & 1.3200 & -0.2081 & 5.0000 & 0.1146 & 0.1037 & 0.6386 & 0.8098 & 1.7782 & 1.4547 & 0.05 \\
\hline CSIRO-Mk3.6.0 & 2.0085 & -0.0361 & 3.7756 & 0.1510 & 0.0137 & 0.0117 & 0.1865 & 17.812 & 1.0633 & 0.49 \\
\hline EC-EARTH & 2.5850 & -0.6157 & 4.9892 & 0.1077 & 0.2489 & 2.4364 & 0.0720 & 19.999 & 1.0624 & 0.05 \\
\hline GFDL-CM3 & 0.1000 & 0.3796 & 5.0000 & 0.1638 & 0.0599 & 2.9073 & 0.3461 & 2.3735 & 1.1692 & 0.18 \\
\hline GFDL-ESM2G & 2.6329 & -1.4040 & 2.1535 & 0.2304 & 1.0000 & 2.2037 & 0.8837 & 20.000 & 1.3555 & 0.15 \\
\hline GFDL-ESM2M & 2.9547 & 1.0000 & 4.9372 & 0.1387 & 0.1479 & 0.0101 & 0.5316 & 7.4830 & 1.1790 & 0.11 \\
\hline GISS-E2-H & 1.2987 & 0.3002 & 1.5682 & 0.4334 & 0.0334 & 0.5996 & 0.9527 & 2.4943 & 1.1256 & 0.07 \\
\hline GISS-E2-HCC & 0.1000 & 1.0000 & 1.4129 & 0.6907 & 0.3571 & 3.7715 & 0.9091 & 17.974 & 1.0928 & 0.11 \\
\hline GISS-E2-R & 0.9151 & 0.9383 & 1.6601 & 0.4458 & 0.1069 & 1.0556 & 1.0000 & 1.5897 & 1.0861 & 0.17 \\
\hline GISS-E2-RCC & 4.9680 & -1.0529 & 1.484 & 0.5898 & 0.1609 & 1.3509 & 0.2843 & 1.3137 & 1.1696 & 0.12 \\
\hline HadGEM2-CC & 0.4727 & -0.0493 & 2.8069 & 0.1638 & 0.5988 & 4.6183 & 0.0246 & 1.2449 & 1.3297 & 0.07 \\
\hline HadGEM2-ES & 0.6165 & 0.0620 & 3.4649 & 0.2123 & 0.3212 & 2.9456 & 0.2779 & 2.3299 & 1.1488 & 0.39 \\
\hline IPSL-CM5A-LR & 1.0928 & -0.0191 & 3.1337 & 0.1181 & 0.2414 & 1.8789 & 0.3740 & 11.705 & 1.0677 & 0.10 \\
\hline IPSL-CM5A-MR & 1.0047 & -0.0643 & 1.5549 & 0.3573 & 0.9473 & 0.7214 & 1.0000 & 15.414 & 1.0472 & 0.09 \\
\hline IPSL-CM5B-LR & 1.6262 & 0.0318 & 5.0000 & 0.1234 & 0.0262 & 6.5424 & 0.1259 & 12.950 & 1.2550 & 0.05 \\
\hline MIROC5 & 2.2396 & 0.5792 & 4.9999 & 0.0961 & 0.4486 & 0.0100 & 0.1234 & 2.8327 & 1.1048 & 0.15 \\
\hline MIROC-ESM & 0.6896 & 0.1877 & 2.0219 & 0.4933 & 0.2884 & 1.4103 & 0.9501 & 3.6729 & 1.1383 & 0.12 \\
\hline MIROC-ESM-CHEM & 0.9997 & -0.5891 & 1.1388 & 1.1193 & 0.0254 & 9.6999 & 0.3022 & 4.4868 & 1.1277 & 0.05 \\
\hline MPI-ESM-LR & 1.7898 & -0.0385 & 3.2976 & 0.2319 & 0.8504 & 1.1209 & 0.2792 & 2.1975 & 1.2154 & 0.33 \\
\hline MPI-ESM-MR & 2.0752 & -1.2640 & 1.4401 & 0.5752 & 0.0510 & 10.000 & 0.5349 & 8.2459 & 1.1122 & 0.06 \\
\hline MPI-ESM-P & 1.3946 & -0.4808 & 4.4931 & 0.0898 & 0.0389 & 10.000 & 0.2498 & 3.9468 & 1.2927 & 0.07 \\
\hline MRI-CGCM3 & 1.4610 & 0.2543 & 4.2439 & 0.1300 & 0.1760 & 5.9552 & 0.0071 & 2.4876 & 1.1478 & 0.05 \\
\hline NorESM1-M & 1.3714 & 0.4972 & 1.404 & 0.4805 & 1.0000 & 3.0676 & 0.2752 & 2.5603 & 1.1744 & 0.11 \\
\hline NorESM1-ME & 2.8281 & 0.6425 & 2.8026 & 0.1382 & 0.2966 & 10.000 & 0.0266 & 15.706 & 1.1203 & 0.08 \\
\hline Mean & 1.3547 & -0.7115 & 1.7022 & 0.3602 & 0.5515 & 9.9876 & 0.2469 & 4.2944 & 0.8823 & 0.05 \\
\hline
\end{tabular}

data. Changes in glacier volume are derived with the help of volume-area scaling methods. In the follow-up study (Marzeion et al., 2014), 2300 estimates of transient glacier mass dynamics forced by 15 CMIP5 temperature and precipitation fields were complemented by equilibrium global glacier projections in response to long-term warming levels from 1 to $10^{\circ} \mathrm{C}$. These two experimental setups projecting transient and equilibrium glacier SLR contributions form the basis of the glacier component that has been implemented in the MAGICC sea level model. We include Randolph Glacier Inventory 4.0 (RGI 4.0) updates on regional glacier mass loss
(Pfeffer et al., 2014). The selected parameterization is based on the assumption that global glacier melt is proportional to the remaining volume susceptible to melt (at the current global temperature) times the melt forcing. This melt forcing is expressed by the temperature difference between current temperature and the temperature that would be expected if the currently remaining glacier volume was in equilibrium. Thus, we apply the following functional form to relate the global glacier SLR response $\mathrm{GL}_{t}$ to the remaining global glacier volume as well as the temperature forcing:

$\mathrm{GL}_{t}=\mathrm{GL}_{t-1}+\kappa\left(V_{\mathrm{eq}}-V_{\mathrm{cum}}\right)\left(T_{t}-T_{\mathrm{eq}}\right)^{v}$ 
with calibration parameters $\kappa$ and $v$ and $V_{\text {eq }}$ being the equilibrium glacier volume change that would result from warming level $T_{t}$. This value is interpolated from the Marzeion et al. (2014) glacier equilibrium response data. $V_{\text {cum }}$ is the cumulative glacier volume change since the year 1850. $T_{\mathrm{eq}}$ is the inverse function of the equilibrium glacier response $V_{\mathrm{eq}}$ to $T_{t}$ and gives the temperature that would lead to the glacier volume change $V_{\text {cum }}$ in terms of a theoretical equilibrium response.

\subsection{Greenland ice sheet}

The Greenland contribution to SLR increased rapidly during the last decades of the 20th century (Vaughan et al., 2013). Regional atmospheric and ocean warming has triggered widespread surface melt (Fettweis et al., 2011) and solid ice discharge (Joughin et al., 2012). An increasingly negative SMB and a growing SLR contribution from SID, which captures accelerating ice stream flow and more frequent calving events due to warmer ocean temperatures, have been identified to be responsible for about half of the observed mass loss each (van den Broeke et al., 2009; Khan et al., 2015). The Greenland ice sheet is expected to become one of the largest SLR contributions in the future (Huybrechts et al., 2011), with potentially irreversible ice-sheet loss for scenarios of persistent and strong warming (Robinson et al., 2012; Levermann et al., 2013). In the following, we present SMB and SID parameterizations that have been implemented and calibrated in the MAGICC sea level model.

\subsubsection{Surface mass balance}

The mass balance at the surface of the Greenland ice sheet is predominantly determined by the accumulation of snowfall in winter and runoff through melting in summer. Continuing global warming will influence the SMB through both increased snowfall and increased melting (Gregory and Huybrechts, 2006). As melting is expected to increase more strongly than snowfall, SMB losses will likely dominate future Greenland contributions to SLR (Church et al., 2013a; Goelzer et al., 2013). Regional surface air temperatures are the primary driver of these projected SMB changes if we assume future precipitation changes over Greenland to be scalable with rising temperatures (Fettweis et al., 2013; Frieler et al., 2012). Regional atmospheric temperatures are closely linked to the global-mean surface air temperature tas. We utilize this link for our sea level component by relating two tasdependent terms to capture the long-term SMB sea level response. In the parameterization, the SMB response to tas can vary from either being approximated as scaling linearly, or nonlinearly with exponent $\varphi$, or as a combination of both. The calibration procedure chooses the optimal balance of the linear and nonlinear terms. Furthermore, the surface melt contribution is damped by diminishing ice availability for high warming scenarios and eventually becomes zero when all available ice is melted. Hence, the cumulative Greenland SMB SLR contribution GIS $t_{t}^{\mathrm{SMB}}$ at time step $t$ can be written as

$$
\begin{aligned}
\mathrm{GIS}_{t}^{\mathrm{SMB}}= & \operatorname{GIS}_{t-1}^{\mathrm{SMB}}+v\left(\chi T_{t}+(1-\chi) T_{t}^{\varphi}\right) \\
& \left(1-\frac{\mathrm{GIS}_{t-1}^{\mathrm{SMB}}}{\mathrm{GIS}_{\max }^{\mathrm{SMB}}}\right)^{0.5} .
\end{aligned}
$$

The maximum Greenland ice volume available for surface melt GIS $\mathrm{max}_{\max }$ is about $7.36 \mathrm{~m}$ (Bamber et al., 2013). The overall temperature sensitivity is denoted by $v$ and the choice of $\varphi$ sets the degree of nonlinearity, while $\chi$ determines the relative magnitude of the linear and nonlinear terms. We calibrate the three parameters $v, \chi$, and $\varphi$ with reference data from Fettweis et al. (2013). Their process-based Greenland SMB projections until 2100 are based on the regional climate model Modele Atmospherique Regional (MAR), which is coupled to the soil-ice-snow-vegetation-atmosphere transfer scheme. The MAR model is forced by CMIP5 data for temperature, wind, humidity, and surface pressure. Comparing the MAGICC Greenland SMB response to millennial projections of Greenland ice-sheet sea level contributions (Huybrechts et al., 2011; Goelzer et al., 2012) indicates that the functional form of our SMB parameterization will hold for multi-centennial projections at least until 2300.

\subsubsection{Solid ice discharge}

Future ocean warming is expected to reduce the frontal stress of the Greenland outlet glaciers while increased melt water from atmospheric warming can reduce the friction at the bottom of these glaciers. Both processes lead to the speed-up and thinning of these glaciers, with increased discharge of solid ice into the oceans (Nick et al., 2009). Even though the SMB contribution is projected to dominate the Greenland contribution to SLR, the SID component has the potential to contribute significantly to SLR (Jacobs et al., 1992; Rignot et al., 2010; Joughin et al., 2012). Recent attempts to quantify the future ice-dynamic SLR contribution for Greenland vary widely, mainly due to different methodologies (Nick et al., 2013; Vizcaino et al., 2015; Fürst et al., 2015). We select one of the key approaches presented in the latest IPCC assessment for our reference data (Church et al., 2013a); Nick et al. (2013) used flow line modeling to project mass loss from Greenland's four main outlet glaciers, Helheim, Jakobshavn Isbrae, Kangerdluqssuaq and Petermann, until 2200. Their model is forced with ocean and atmosphere data from SRES A1B and RCP8.5 scenario runs conducted with the CMIP3 model ECHAM5-OM. As the four main outlet glaciers drain about $20 \%$ of the entire Greenland ice-sheet area, the sum of the individual glacier contributions has been multiplied by a factor of 5 to estimate the SID sea level contribution of the whole ice sheet (Church et al., 2013a; Price et al., 2011). We use the same approach to emulate the response of Nick et al. (2013), with the cumulative Greenland SID SLR contribution 
$\operatorname{GIS}_{t}^{\mathrm{SID}}$ at time step $t$ being:

$\mathrm{GIS}_{t}^{\mathrm{SID}}=s\left(\mathrm{GIS}_{\max }^{\text {outlet }}-\mathrm{GIS}_{\mathrm{Vdis}(t)}^{\text {outlet }}\right)$

with GIS $_{t}^{\text {SID }}$ defined as the difference of the initial maximum ice volume susceptible to discharge and the remaining ice volume available for discharge at time step $t$. Maximum ice volume, GIS max $_{\max }$, and remaining ice volume at time step $t$, GIS $_{\text {Vdis }(t)}^{\text {outlet }}$, are determined for the four main Greenland outlet glaciers. By applying the scaling factor $s=5$, the sea level contribution is then scaled up to the entire Greenland ice sheet. For $t=0, \operatorname{GIS}_{\operatorname{Vdis}(t=0)}^{\text {outlet }}=\operatorname{GIS}_{\max }^{\text {outlet }}$. The remaining ice volume susceptible to discharge at time step $t, \operatorname{GIS}_{\mathrm{Vdis}(t)}^{\text {outlet }}$, has the following function form:

$$
\begin{aligned}
\operatorname{GIS}_{\mathrm{Vdis}(t)}^{\text {outlet }}= & \mathrm{GIS}_{\mathrm{Vdis}(t-1)}^{\text {outlet }} \\
& -\max \left(0, \varrho \mathrm{GIS}_{\mathrm{Vdis}(t-1)}^{\text {outlet }} e^{\epsilon T_{(t-1)}}\right)
\end{aligned}
$$

with the annual discharge being the product of the discharge sensitivity $\varrho$, the SID volume $\operatorname{GIS}_{\operatorname{Vdis}(t-1)}^{\text {outlet }}$ available at time step $t-1$, and an exponential tas term, which is dependent on a temperature sensitivity $\epsilon$. We have calibrated $\varrho, \epsilon$, and the maximum SID outlet glacier volume GIS max $_{\max }$ based on the projected minimum and maximum contributions for dynamic retreat and thinning for scenarios SRES A1B and RCP8.5, shown in Fig. 3e of Nick et al. (2013). An upper limit of the potential Greenland SID discharge contribution has not been clearly defined yet (Goelzer et al., 2013; Price et al., 2011). We include the maximum SID outlet glacier volume susceptible to discharge GIS $\max _{\max }$ in our calibration. Applying the scaling suggested by Church et al. (2013a), our total Greenland SID maximum ice discharge volumes amount to around 180 and $268 \mathrm{~mm}$ SLE for the minimum and maximum cases presented in Nick et al. (2013). For comparison, Winkelmann and Levermann (2012) obtained $420 \mathrm{~mm}$ for the ice-dynamic Greenland sea level contribution, indicating, however, that the actual amount might be significantly smaller. For high warming scenarios, our SID projections deplete GIS max $_{\max }$ before the year 2300, which causes the annual Greenland SID sea level contribution to drop to zero.

\subsection{Antarctic ice sheet}

Air temperatures over the Antarctic ice sheet are generally much colder than over the Greenland ice sheet. They will be too low to cause wide-spread surface melting, even under strong global warming (Church et al., 2013a). Only peripheral, low-lying glaciers, especially around the Antarctic Peninsula are susceptible to retreat through increased ablation (Krinner et al., 2006). A warmer atmosphere over Antarctica will however hold more moisture, leading to higher snowfall. This effect is expected to lead to a positive SMB through snow accumulation and, thus, a slightly negative SLR contribution (Bengtsson et al., 2011; Gregory and Huybrechts, 2006). The main driver of Antarctic ice loss and a resulting positive sea level contribution is the increased melting of ice shelves through warmer ocean waters (Joughin et al., 2012; Bindschadler et al., 2013). SID will be the dominant SLR contribution of Antarctica, with increasing ocean temperatures causing basal melt in marine-based ice-sheet sectors, potentially even triggering marine ice-sheet instabilities and irreversible ice loss (Huybrechts et al., 2011; Joughin et al., 2014). We implemented parameterizations capturing both the Antarctic SMB and the SID contributions to SLR in the MAGICC SLR mode. They are presented below.

\subsubsection{Surface mass balance}

Positive Antarctic SMB anomalies under all warming scenarios lead to consistently negative contributions to global sea level for the 21 st century. Similar to Greenland, a strong (but different) link exists between future Antarctic SMB and global-mean surface air temperature tas. Several studies confirmed the Clausius-Clapeyron equation-based exponential relationship between atmospheric warming and SMB accumulation. The values range from $3.7 \%{ }^{\circ} \mathrm{C}^{-1}$ (Krinner et al., 2006) up to around $7 \%{ }^{\circ} \mathrm{C}^{-1}$ (Bengtsson et al., 2011), with most recent estimates based on a large ensemble of climate models pointing to about $5 \%{ }^{\circ} \mathrm{C}^{-1}$ (Frieler et al., 2016). Ligtenberg et al. (2013) has been one of the few studies using regional climate simulations to assess Antarctic SMB changes beyond 2100, without accounting for climateice-sheet feedbacks however. Their assessment is based on the regional atmospheric climate model RACMO2 (Lenaerts et al., 2012) and the two global climate models ECHAM5 (Roeckner et al., 2003) and HadCM3 (Johns et al., 2003) that have been forced by two comparably moderate emission scenarios (SRES A1B and ENSEMBLES E1), leading to a 2200 Antarctic warming of $2.4-5.3^{\circ} \mathrm{C}$. Results show SMB increases of $8-25 \%$, which translate into a global sea level drop of 73-163 mm. We select these projections as reference for our SMB parameterization. Due to the expected strong SMB link to tas, we have chosen a simple functional form that relates the annual Antarctic SMB sea level contribution to this primary driver:

$\mathrm{AIS}_{t}^{\mathrm{SMB}}=\mathrm{AIS}_{t-1}^{\mathrm{SMB}}+\xi\left(\rho T_{t}+(1-\rho) T_{t}^{\sigma}\right)$.

The annual change in the Antarctic SMB contribution to SLR is derived from the sum of a linear and nonlinear tas term, calibrated with the three parameters $\xi, \rho$, and $\sigma$. The transfer from global-mean tas to regional surface air temperature changes as well as the translation of air temperatures into snowfall accumulation is captured in $\xi$, while $\rho$ controls the nonlinearity of the parameterization. The calibrated parameterization is then used to extend Antarctic SMB SLR estimates until 2300 presuming that the rationale behind the projections presented in Ligtenberg et al. (2013) hold for another 100 years. This is consistent with findings from up to 3000-year-long Antarctic SMB simulations that are forced 
by idealized scenarios doubling or quadrupling atmospheric $\mathrm{CO}_{2}$ concentration levels (Vizcaíno et al., 2010; Huybrechts et al., 2011). Results from these studies show ice mass gains due to additional snowfall for more than 500 years after the start of the experiments, e.g., see Fig. 7 in Huybrechts et al. (2011).

\subsubsection{Solid ice discharge}

Improved process understanding has allowed for a first assessment of the Antarctic dynamic ice-discharge contribution to SLR in the fifth IPCC Assessment Report (Church et al., 2013a). Antarctic SID has the potential to supersede all other sea level contributions because of the vast ice masses accessible for warm ocean waters and susceptible to self-amplified retreat (DeConto and Pollard, 2016). Loss of these ice masses alone would eventually lead to several meters of global SLR (Bamber et al., 2009). Recent observations and modeling suggests that the process of self-sustained retreat has already begun and will dominate over the slower adjustments to tas and precipitation changes across the Antarctic continent on decadal to centennial timescales (Joughin et al., 2014; Rignot et al., 2014; Favier et al., 2014). Levermann et al. (2014) convolved the responses from five different Antarctic ice-sheet models to basal melt forcing as used in the SeaRISE project (Bindschadler et al., 2013) with a large set of MAGICC temperature projections for the full suite of RCP scenarios. In their study, the projected global-mean tas signal is converted into subsurface ocean temperatures that are translated into basal melt forcing. The melt forcing is then convolved with individual response functions for the Amundsen Sea, Ross Sea, Weddell Sea, and East Antarctic sectors. This approach is well-suited for the MAGICC sea level model implementation because it relates the ice-sheet response directly to tas. We implement a step-wise convolution routine in the MAGICC SLR model, which allows us to process the response functions for the different sectors. The total SLR contribution from Antarctic SID, AIS ${ }^{\text {SID }}$, can be written as the sum of the contributions from the individual sectors:

$\mathrm{AIS}^{\mathrm{SID}}=\sum_{n=1}^{4} \int_{0}^{t} F_{n}(\tau) R_{n}(t-\tau) \mathrm{d} \tau$.

The sector-specific basal melt forcing $F_{n}$ is the product of the basal melt sensitivity $\psi$ and the sector-specific subsurface ocean temperature anomaly $\mathrm{d} T_{\mathrm{OCN}}$. The region-specific icesheet response function $R_{n}(t-\tau)$ is based on linear response theory (Winkelmann and Levermann, 2012). The basal melt forcing $F$ is the product of the basal melt sensitivity $\psi$ and the sector-specific subsurface ocean temperature anomaly $\mathrm{d} T_{\mathrm{OCN}}$. Starting in 1850, Levermann et al. (2014) derived the latter from the projected annual MAGICC global-mean tas anomalies via ocean temperature scaling and a time delay between surface and ocean subsurface warming. We adopt all relevant melt forcing parameters from Levermann et al.
(2014). They determined these parameters either through calibrations against 19 CMIP5 models or adopted them from the existing literature, such as the basal melt sensitivities ranging from 7 to $16 \mathrm{~m} \mathrm{a}^{-1} \mathrm{~K}^{-1}$ (Holland et al., 2008; Payne et al., 2007; Jenkins, 1991). The response functions are derived for 500 years and cover the time frame of their source experiments described in Bindschadler et al. (2013). We provide Antarctic SID projections up to the year 2300. For the MAGICC component, it is only response functions from the three ice-sheet models that have an explicit representation of ice-shelf dynamics that is included, namely PennState3D (Pollard and DeConto, 2012), PISM (Winkelmann et al., 2011; Martin et al., 2011), and SICOPOLIS (Sato and Greve, 2012). The response functions presented by Levermann et al. (2014) and implemented here do not account for all ice-sheet processes and feedbacks. Thus, the Antarctic SID estimates provided by the MAGICC sea level model may underestimate the actual Antarctic SID sea level response.

\subsection{Land water storage}

The assessment of the observed and projected anthropogenic land water contribution to SLR is subject to ongoing discussions (Konikow, 2011; Pokhrel et al., 2012; Wada et al., 2012, 2016; Church et al., 2013a). Associated uncertainties are high, mainly due to sparse data coverage and incomplete process understanding. Two major processes drive changes in land water storage: the depletion of groundwater resources, which positively contributes to SLR, and water impoundment which damps the SLR signal. Analyses show that the latter contribution has been shrinking since the late 20th century (Gregory et al., 2013b), which leaves groundwater depletion as the main human-driven land water storage (LWS) SLR contribution throughout the 21 st century and beyond. We include the option to provide LWS sea level estimates based on the approach introduced by Wada et al. (2012). They forced the hydrological model PCR-GLOBWB (van Beek et al., 2011) with climate projections from AOGCMs to derive estimates for future groundwater depletion until 2100. Original estimates had to be revised because only roughly $80 \%$ of annually depleted groundwater ends up in the oceans (Wada et al., 2016). We adapt our time series accordingly, reducing the Wada et al. (2012) sea level contribution estimates from groundwater depletion by $20 \%$. We use the 30-year average annual depletion rate for the period 2071-2100 to extend the projections beyond the 21 st century. We assume that projected rates of human water use and groundwater abstraction, which show more constant rates towards the end of the 21st century (Wada, 2016), will persist beyond 2100. The fraction of non-renewable groundwater to total groundwater abstraction is projected to increase to around $50 \%$ by 2100 (Wada, 2016). This indicates that, ultimately, the total amount of groundwater available for abstraction is limited. To account for such an upper bound of the LWS sea level contribution, we use a term that relates the cumulative 
LWS contribution to a theoretical maximum LWS volume that can be depleted. No distinction is made between different climate scenarios for the post-2100 LWS extension due to the limited process understanding and the associated large uncertainties (Church et al., 2013a). Hence, we implement the revised Wada et al. (2012) estimates until 2100 and apply the following post-2100 LWS parameterization:

$$
\begin{aligned}
\mathrm{LWS}_{t}= & \mathrm{LWS}_{t-1}+\mathrm{LWS}_{\mathrm{const}} \\
& \left(1-\frac{\mathrm{LWS}_{t-1}-\mathrm{LWS}_{2100}}{\mathrm{LWS}_{\text {max }}-\mathrm{LWS}_{2100}}\right)^{0.5} .
\end{aligned}
$$

The maximum LWS volume LWS $_{\max }$ has not been quantified yet de Graaf et al. (2014). However, Gleeson et al. (2015) quantified the amount of modern groundwater, which is defined as less than 50-year-old groundwater located in the top $2 \mathrm{~km}$ of the continental crust. This type of groundwater dominates the interaction with general hydrological cycle and the climate system. It is also the most accessible for land use (Gleeson et al., 2015). We here define LWS $_{\max }$ as the total amount of available modern groundwater, which has been estimated to be around $350000 \mathrm{~km}^{3}$, roughly translating to $1000 \mathrm{~mm}$ SLE.

\subsection{Model calibration}

For the MAGICC ocean model calibration, we use two CMIP5 variables for our reference dataset: ocean potential temperatures (thetao) and thermal expansion (zostoga). Ocean-depth-specific thetao time series are extracted for a total of 36 CMIP5 models, which have been running preindustrial control (pictrl), historical, some or all of the RCP experiments as well as the idealized $1 \% \mathrm{CO}_{2}$ per year increase (1pctCO2) experiments. Each individual model output is converted into hemispheric annual-mean thetao depth profile time series that are then vertically interpolated to match the MAGICC ocean-layer depths. We combine historical and RCP runs to create layer-specific time series from 1850 to 2100 or 2300 depending on the experiment lengths of the individual CMIP5 model runs. Ocean temperature data available from the CMIP archives are subject to drift because the time scales for the ocean to adjust to external forcing are much longer than the length of the control experiments (Taylor et al., 2012; Gupta et al., 2013). Individual model drifts have been identified based on the respective pictrl runs. The full linear trend from the pictrl experiments has been removed from the historical plus RCP and 1pctCO2 scenario time series.

The initial thetao profiles are prescribed for every CMIP5 model calibration as well as the respective depth-dependent ocean area fractions. We incorporate zostoga estimates for each of the 36 CMIP5 ensemble members by detrending the times series with the full linear trend of the pictrl runs. To ensure a full CMIP5-consistent calibration setup, we constrain MAGICC for every CMIP5 model optimization by prescribing the corresponding model-specific annual global-mean surface air temperature tas. Previous studies have shown that calibration methods for highly parameterized simple models do successfully show global convergence, even with a large number of free parameters (Hargreaves and Annan, 2002; Meinshausen et al., 2011a). Here, we select all MAGICC parameters, which directly determine the ocean-layer-specific potential ocean temperature and corresponding thermal expansion responses. These nine parameters drive the band routine of the hemispheric upwelling-diffusion ocean model. The vertical thermal diffusivity, $K_{z}$, its sensitivity to globalmean surface temperatures at the mixed-layer boundary, $\frac{\mathrm{d} K_{z_{\text {top }}}}{\mathrm{d} T}$, the sea-ice adjustment parameters $\eta$ and $\gamma$ described above, the initial upwelling rate $w_{0}$, the ratio of changes in the temperature of the entraining waters to those of the polar sinking waters $\beta$, the ratio of variable to fixed upwelling $\frac{\Delta w_{t}}{w_{t}}$, and the corresponding threshold temperatures that lead to constant upwelling rates, namely $T_{w_{t}}$, and the global thermal expansion scaling coefficient $\phi$. The minimum vertical diffusivity $K_{z, \min }$ is set to $0.1 \mathrm{~cm}^{2} \mathrm{~s}^{-1}$, as stated in Meinshausen et al. (2011a). This value represents the lower bound for the calibration of $K_{z}$. More details on the individual parameters can be found in Meinshausen et al. (2011a) except for the sea-ice adjustment variables described in Sect. 2.1. For every CMIP5 model, this suite of calibration parameters is optimized based on the scenario-specific CMIP5 thetao data for the representative layers 1 (30 m layer-mean depth), 2 (110 m), 3 (210 m), 8 (710 m), 15 (1410 m), 30 (2910 m), and $40(3910 \mathrm{~m})$, and the corresponding zostoga time series. The eight calibration layers have been selected to allow the MAGICC ocean model to emulate the key features of the CMIP5 ocean temperature profiles, with the majority of calibration layers set in the upper ocean to ensure sufficient coverage of the stronger temperature gradients. The number of reference layers is not increased further to preserve computational efficiency; 5000 random parameter sets are drawn prior to each model optimization procedure. The number of initial random runs has been determined through iterative testing to ensure convergence to a global optimum. The resulting best fit is subsequently used for the initialization of the automated Nelder-Mead simplex optimization routine (Lagarias et al., 1998; Nelder and Mead, 1965) with a termination tolerance of $10^{-8}$ and a maximum iteration number of 10000 . We use weighted residual sum of squares (RSS) for goodness-of-fit (GOF) diagnostics during the optimization process (Meinshausen et al., 2011a). The ocean calibration also takes into account the available CMIP5 zostoga time series. The zostoga optimization component is given 4 orders of magnitude less relative weight than the thetao component in order to prioritize the accurate layer-by-layer emulation of the respective CMIP5 model thetao time series. The GOF values are then divided by the number of calibrated model years, accounting for the varying amount of scenario data available for each model. This allows us to compare the GOFs of the calibrations for all 36 CMIP5 models. 
The calibration procedures for the other SLR components also optimize the specific parameters listed in Tables 2 to 5 based on the Nelder-Mead Simplex method with a termination tolerance of $10^{-8}$ for a change in RSS during the last iteration. For an overview of all relevant variables and calibration parameters please see Table A1. All the remaining SLR components use reference SLE contributions in millimeters for the respective optimizations. For the glacier contribution, the MAGICC sea level response is fitted to the transient Marzeion et al. (2014) projections. The free parameters $\kappa$ and $v$ are calibrated for each of the 14 CMIP5 reference models and their respective combined historical and RCP simulations, starting in 1850. Corresponding CMIP5 global-mean tas projections are prescribed in the MAGICC model to ensure consistency with CMIP5. We use a subset of the model-specific 1965-2100 projections made available by Fettweis et al. (2013) to calibrate the parameterization for the Greenland SMB contribution. In total, 24 CMIP5 models are selected based on the availability of CMIP5 tas projections for the scenarios RCP4.5 and RCP8.5. We then prescribe these global-mean tas time series for the calibration procedure of the three parameters $v, \chi$, and $\varphi$. Calibration data for the Greenland SID component is only available for one GCM, ECHAM5. For the optimization of the parameters $\varrho, \epsilon$, and GIS $\mathrm{m}_{\max }^{\text {outet }}$, global-mean tas runs for SRES A1B and RCP8.5 are used with 2200 extensions, repeating the last decade of the 21st century 10 times (Nick et al., 2013). The calibration of the Antarctic SMB component is based on process-based SLR responses forced by two GCMs (Ligtenberg et al., 2013). In this reference study, ECHAM5 and HadCM3 model output was applied for scenarios SRES A1B and ENSEMBLES E1. We replicate these GCM responses and use the provided Antarctic SMB sea level contributions starting in 1980 to determine the optimal parameters $\xi, \rho$, $\sigma$. The Antarctic SID as well as the LWS components are not subject to calibration procedures as they apply the same method of the reference study in the case of Antarctic SID or simply include and extend the reference data for LWS.

\section{Results}

The MAGICC ocean model update yields optimal parameter sets for every CMIP5 model used in the calibration procedure outlined above. Those sets are listed in Table 1. In Fig. 2, we show both the $90 \%$ model range and the median for the reference CMIP5 global potential ocean temperature anomalies as well as the median MAGICC global ocean warming profile averaged over 2081 to 2100 relative to the reference period 1986 to 2005 . The figure also provides information on individual model outliers for reference data and calibration results. Corresponding potential ocean temperature residuals are shown in Fig. A1. MAGICC is able to capture the key CMIP5 features for all RCP scenarios. The median model response either matches or is close to the me-
Table 2. Glacier sea level component calibration results with parameter sets for the available CMIP5 models. Calibration parameters are introduced in Sect. 2.6. GOF is given as weighted RSS divided by the number of calibrated model years (weight glacier SLE contribution [mm]: 1). The optimal set for the mean response of the calibration data is given at the bottom of the table.

\begin{tabular}{lrrr}
\hline Model & $\kappa$ & $v$ & GOF \\
\hline BCC-CSM1.1 & 0.0131 & 0.1551 & 51.88 \\
CanESM2 & 0.0098 & 0.1742 & 27.22 \\
CCSM4 & 0.0104 & 0.2743 & 6.935 \\
CNRM-CM5 & 0.0101 & 0.2217 & 122.8 \\
CSIRO-Mk3.6.0 & 0.0088 & 0.2963 & 120.1 \\
GFDL-CM3 & 0.0125 & 0.1932 & 6.061 \\
GISS-E2-R & 0.0116 & 0.0955 & 11.81 \\
HadGEM2-ES & 0.0114 & 0.2961 & 50.19 \\
IPSL-CM5A-LR & 0.0091 & 0.2260 & 33.82 \\
MIROC5 & 0.0126 & 0.1198 & 12.77 \\
MIROC-ESM & 0.0099 & 0.1402 & 23.91 \\
MPI-ESM-LR & 0.0079 & 0.4451 & 25.04 \\
MRI-CGCM3 & 0.0081 & 0.1885 & 13.10 \\
NorESM1-M & 0.0106 & 0.1126 & 34.04 \\
\hline Mean & 0.0106 & 0.0788 & 6.10 \\
\hline
\end{tabular}

dian of the CMIP5 responses. The updated MAGICC ocean deviates from the CMIP5 data in a few cases. Generally, there appears to be less warming in the mid-ocean between around $1500 \mathrm{~m}$ and $2500 \mathrm{~m}$ than in the CMIP5 reference data. Also, there is a tendency for the MAGICC bottom layers to warm more than the CMIP5 reference data. However, it is only for two of the 36 CMIP5 models used that calibration results show a major bottom layer warming bias. The GISSE2-R reference data show strong mid-layer warming combined with actual bottom layer cooling, while the HadGEM2$\mathrm{CC}$ data show cooling in the upper $500 \mathrm{~m}$ over the historical period (see Fig. A2). In both cases, the MAGICC hemispheric upwelling-diffusion ocean model cannot fully capture these characteristics. For the HadGEM2-CC emulation, MAGICC overcompensates the surface cooling with strong bottom layer warming. Apart from these anomalies, the calibrated MAGICC ocean component captures the hemispherically averaged CMIP5 ocean warming for the different RCP scenarios well (Figs. 2 and A1). We derive CMIP5-consistent thermal expansion estimates based on the optimal ocean parameter sets and the additional thermal expansion scaling parameter $\phi$ (see Table 1).

In Fig. 3, we synthesize the calibration results for all sea level contributions captured by the MAGICC sea level model. Panels (a) to (d) show the model-specific global thermal expansion responses and the corresponding CMIP5 zostoga reference data for the four RCP scenarios. The number of available reference runs differs for each scenario as does the length of the simulations. The updated MAGICC ocean component is able to mimic the CMIP5 thermal ex- 


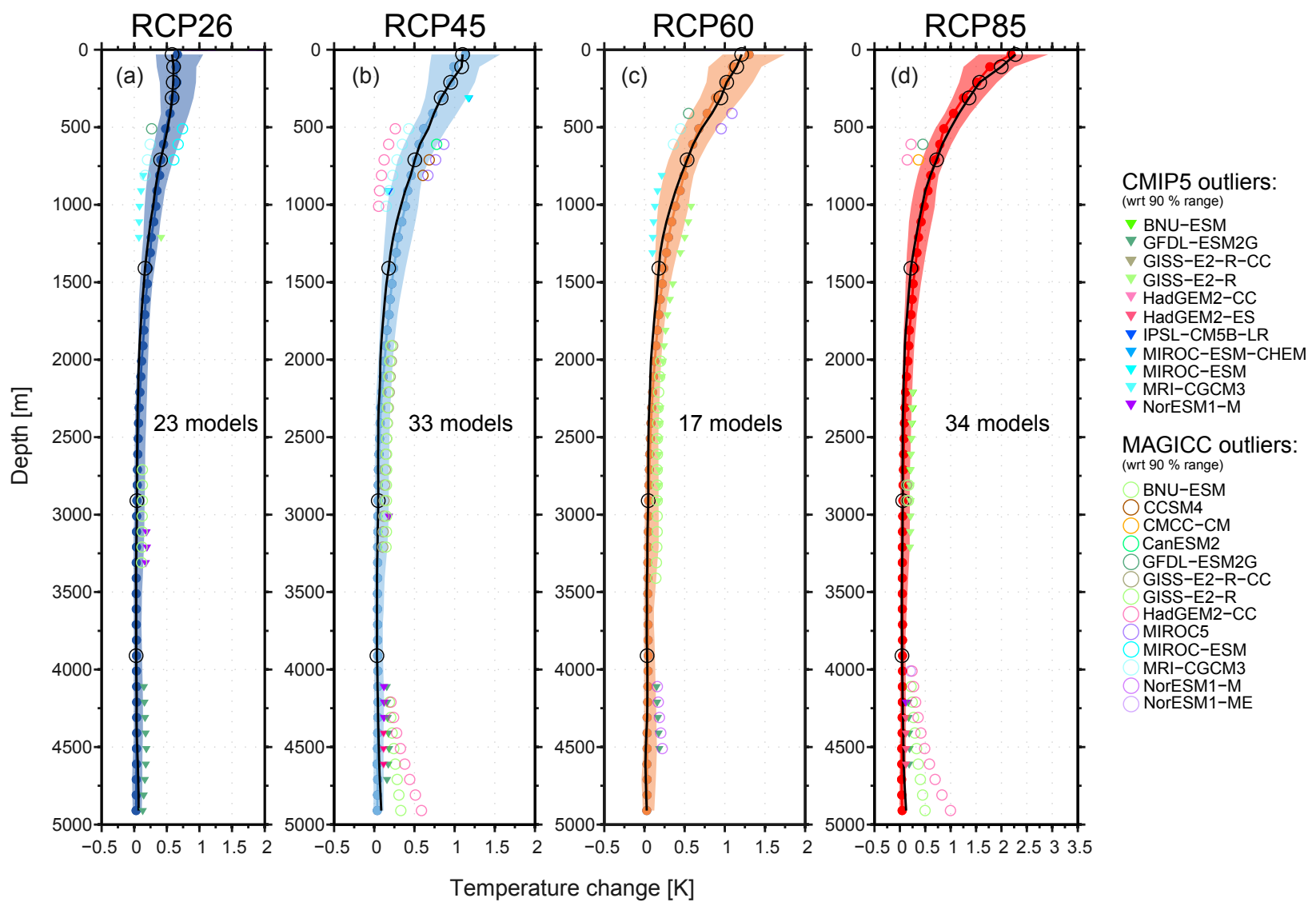

Figure 2. Potential ocean temperature depth profiles for MAGICC and reference CMIP5 warming under RCP2.6, RCP4.5, RCP6.0, and RCP8.5 scenarios, 2081-2100 anomalies with respect to 1986-2005. Interpolated CMIP5 $90 \%$ model ranges and corresponding median profiles are shown in colors, with circles indicating the individual MAGICC ocean layers. MAGICC median ocean-warming profiles given as black lines with open circles indicating selected layers for ocean calibration. Model outliers not covered by the respective $90 \%$ ranges are shown for both CMIP5 reference data and MAGICC calibration results. Potential ocean temperature residuals of the calibration are provided for every MAGICC ocean layer in Fig. A1.

pansion time series. Relative to 1850 , the calibration yields a 2100 thermosteric SLR range of 104 to $238 \mathrm{~mm}$ (CMIP5: 113 to $231 \mathrm{~mm}$ ) for RCP2.6, 151 to $307 \mathrm{~mm}$ (161 to $290 \mathrm{~mm}$ ) for RCP4.5, 166 to $331 \mathrm{~mm}$ (174 to $309 \mathrm{~mm}$ ) for RCP6.0, and 219 to $491 \mathrm{~mm}$ (261 to $445 \mathrm{~mm}$ ) for RCP8.5. The corresponding 1850 to 2300 thermosteric SLR responses range from 192 to $335 \mathrm{~mm}$ for RCP2.6 (CMIP5: 180 to $288 \mathrm{~mm}$ ), 348 to $709 \mathrm{~mm}$ for RCP4.5 (345 to $707 \mathrm{~mm}$ ), 586 to $717 \mathrm{~mm}$ for RCP6.0 (635 to $658 \mathrm{~mm}$ ), and 1040 to $1794 \mathrm{~mm}$ for RCP8.5 (1040 to $1909 \mathrm{~mm}$ ). In contrast to some detrended zostoga CMIP5 model time series, the MAGICC thermal expansion projections do not show negative slopes in the 20th century, which is consistent with observations (Church et al., 2013b).

The calibrated global glacier SLR response and the corresponding reference data are shown in panels (e) to (h), while the specific calibration results are listed in Table 2. The MAGICC projections show good agreement with the updated Marzeion et al. (2012) data (Fig. 3e to h). Relative to 1850 , the estimated glacier SLE contributions in 2100 are 145 to $259 \mathrm{~mm}$ (Marzeion et al., 2014: 134 to $256 \mathrm{~mm}$ ) for RCP2.6, 162 to $276 \mathrm{~mm}$ ( 159 to $277 \mathrm{~mm}$ ) for RCP4.5, 163 to 276 (163 to $276 \mathrm{~mm}$ ) for RCP6.0, and 188 to $302 \mathrm{~mm}$ (198 to $308 \mathrm{~mm}$ ) for RCP8.5. For 2300, projected SLR from glaciers amounts to a SLE range of 177 to $298 \mathrm{~mm}$ (Marzeion et al., 2014: 188 to $305 \mathrm{~mm}$ ) for RCP2.6, 255 to $374 \mathrm{~mm}$ ( 254 to $366 \mathrm{~mm}$ ) for RCP4.5, and 325 to $439 \mathrm{~mm}$ ( 338 to $444 \mathrm{~mm}$ ) for RCP8.5.

In panels (j) and (k), we cover the Greenland SMB contribution, both the reference data from Fettweis et al. (2013) and the sea level model estimates based on the optimal parameter sets shown in Table 3. Our model shows high agreement with the reference data. For 2100, we project SLE ranges from 18 to $117 \mathrm{~mm}$ (Fettweis et al., 2013: 17 to $114 \mathrm{~mm}$ ) based on RCP4.5 and SLE ranges from 49 to 208 (48 to $206 \mathrm{~mm}$ ) based on RCP8.5. Projections start in 1965, being the first year of the calibration data. The Greenland SID calibration results are depicted in Fig. 31 and m. We show MAGICC sea level model estimates based on the cali- 

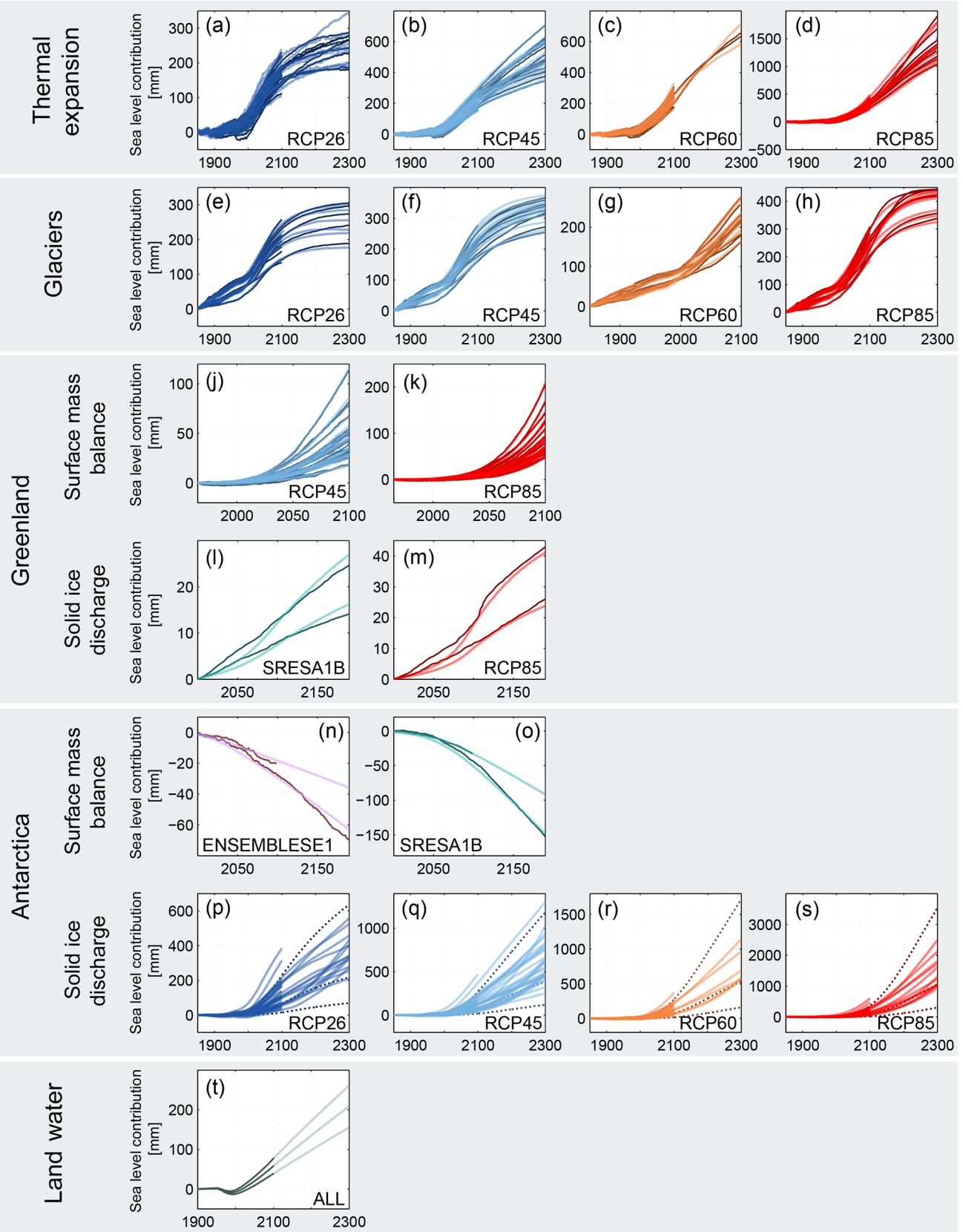

Figure 3. MAGICC sea level model calibration results for thermal expansion (a-d), global glaciers (e-h), Greenland surface mass balance (jk) and solid ice discharge (1-m), Antarctic surface mass balance (n-o), and solid ice discharge (p-s), as well as land water (t). The panels show scenario-specific calibrated MAGICC sea level responses as colored lines, with underlying reference data as thin dark lines. Antarctic solid ice discharge reference $90 \%$ range plus corresponding median are provided as thin dashed lines. Climate-independent land water projections are identical to the reference data until 2100 (see Sect. 2.5). Please note that $x$ and $y$ axis ranges differ for individual panels.

bration results listed in Table 4. As presented by Nick et al. (2013), we show projections of the minimum and maximum cases for the combined contribution from the four major outlet glaciers prior to up-scaling to the entire Greenland ice sheet. Estimates are provided relative to the year 2000. For the SRES A1B scenario, the SLE projections range from 17 to $28 \mathrm{~mm}$ (Nick et al., 2013: 14 to $25 \mathrm{~mm}$ ) for the last year of the available reference data in 2190 . For the same year, we project 24 to $42 \mathrm{~mm}$ ( 26 to $43 \mathrm{~mm}$ ) based on the RCP 8.5 scenario.

Calibration results for the Antarctic SMB component, which negatively contributes to future SLR, are listed in Table 5. Corresponding output is shown in panels (n) and (o). Starting in 1980, the reference data from Ligtenberg et al. 
Table 3. Greenland SMB sea level component calibration results with optimal parameter sets for the available CMIP5 models. Calibration parameters are introduced in Sect. 2.6. GOF is given as weighted RSS divided by the number of calibrated model years (weight Greenland SMB SLE contribution [mm]: 1). The optimal set for the mean response of the calibration data is given at the bottom of the table.

\begin{tabular}{lrrrr}
\hline Model & $v$ & $\chi$ & $\varphi$ & GOF \\
\hline ACCESS1.0 & 0.2190 & 0.9748 & 3.2749 & 0.74 \\
ACCESS1.3 & 0.2021 & 0.2490 & 1.2781 & 0.46 \\
BCC-CSM1.1 & 0.0664 & 0.2398 & 2.3731 & 0.56 \\
BNU-ESM & 0.1290 & 0.0000 & 1.9068 & 0.89 \\
CanESM2 & 0.0656 & 0.0000 & 2.2971 & 1.96 \\
CCSM4 & 0.0186 & 0.0000 & 2.7122 & 1.17 \\
CESM1-BGC & 0.0618 & 0.0000 & 1.9517 & 1.06 \\
CMCC-CM & 0.0830 & 0.0000 & 1.9688 & 1.57 \\
CNRM-CM5 & 0.1009 & 0.0000 & 1.8283 & 0.36 \\
CSIRO-Mk3.6.0 & 0.1459 & 0.4702 & 1.8740 & 0.60 \\
GFDL-CM3 & 0.3347 & 0.7326 & 2.2962 & 0.56 \\
GFDL-ESM2M & 0.1077 & 0.0000 & 2.0794 & 0.90 \\
GISS-E2-R & 0.1302 & 0.0000 & 1.9605 & 0.26 \\
HadGEM2-CC & 0.2308 & 0.9594 & 2.9988 & 0.27 \\
HadGEM2-ES & 0.1974 & 0.8354 & 2.2872 & 0.55 \\
IPSL-CM5A-LR & 0.1762 & 0.4514 & 1.8847 & 0.25 \\
IPSL-CM5A-MR & 0.0802 & 0.0000 & 2.0480 & 0.67 \\
IPSL-CM5B-LR & 0.0531 & 0.0000 & 2.4263 & 0.99 \\
MIROC5 & 0.2168 & 0.0000 & 1.8440 & 1.11 \\
MIROC-ESM-CHEM & 0.1557 & 0.3454 & 2.1621 & 1.51 \\
MIROC-ESM & 0.1549 & 0.5188 & 2.3107 & 1.10 \\
MPI-ESM-LR & 0.0333 & 0.0000 & 2.6372 & 1.49 \\
MRI-CGCM3 & 0.0645 & 0.0000 & 2.2958 & 0.59 \\
NorESM1-M & 0.0969 & 0.0000 & 2.0000 & 0.50 \\
\hline Mean & 0.1148 & 0.0000 & 2.0169 & 0.47 \\
\hline
\end{tabular}

Table 4. Greenland SID sea level component calibration results with optimal parameter sets for the low and high cases introduced by Nick et al. (2013). Calibration parameters are introduced in Sect. 2.6. GOF is given as weighted RSS divided by the number of calibrated model years (weight Greenland SID SLE contribution [mm]: 1).

\begin{tabular}{lrrrr}
\hline Case & $\varrho$ & $\epsilon$ & $\begin{array}{r}\text { GIS outlet } \\
\text { [mm }\end{array}$ & GOF \\
\hline Low & $9.062 \times 10^{-4}$ & 0.3891 & 35.98 & 0.81 \\
High & $7.933 \times 10^{-4}$ & 0.4722 & 53.63 & 1.62 \\
\hline
\end{tabular}

(2013) provides projections that go beyond 2100 only for the model HadCM3. For the ENSEMBLES E1 scenario, the two model-specific 2100 SLE responses range from -29 to $-18 \mathrm{~mm}$ (Ligtenberg et al., 2013: -27 to $-20 \mathrm{~mm}$ ). The 2200 estimate lies at $-67 \mathrm{~mm}(-73 \mathrm{~mm})$ based on the HadCM3 parameter set. The 2100 values for the SRES A1B scenario span from -51 to $-33 \mathrm{~mm}$ (Ligtenberg et al., 2013: -44 to $-32 \mathrm{~mm}$ ), while the 2200 Antarctic SMB SLE re-
Table 5. Antarctic SMB sea level component calibration results with optimal parameter sets for the CMIP3 models ECHAM5 and HadCM3. Calibration parameters are introduced in Sect. 2.6. GOF is given as weighted RSS divided by the number of calibrated model years (weight Antarctic SMB SLE contribution [mm]: 1). The optimal set for the mean response of the calibration data is given at the bottom of the table.

\begin{tabular}{lrrrr}
\hline Model & $\xi$ & $\rho$ & $\sigma$ & GOF \\
\hline ECHAM5 & -0.11028 & 0.0000 & 1.2435 & 0.70 \\
HadCM3 & -0.13869 & 0.0000 & 1.3910 & 9.61 \\
\hline Mean & -0.12082 & 0.0000 & 1.5234 & 0.70 \\
\hline
\end{tabular}

sponse is projected to be $-158 \mathrm{~mm}(-163 \mathrm{~mm})$. As we model the Antarctic SID sea level component with the linear response function approach presented by Levermann et al. (2014), it is not calibrated against any reference data. The MAGICC component utilizes the responses from the three ice-sheet models of that study, which include an explicit representation of ice-shelf dynamics. As the sea level responses for this subset of ice-shelf models are not available, we show the $90 \%$ model range and the median of all five ice-sheet models from Levermann et al. (2014) in Fig. 3p to s. CMIP5 model-specific parameter sets have been determined for the three different ice-shelf models (Levermann et al., 2014, Tables 2-5). For 1850 to 2100 , the $90 \%$ ranges of the MAGICC responses based on the ice-shelf model subset correspond to 33 to $253 \mathrm{~mm}$ SLE (Levermann et al., 2014: 15 to $227 \mathrm{~mm}$ ) for RCP2.6, 39 to $319 \mathrm{~mm}$ ( 17 to $267 \mathrm{~mm}$ ) for RCP4.5, 42 to $338 \mathrm{~mm}$ (17 to $277 \mathrm{~mm}$ ) for RCP6.0, and 53 to $448 \mathrm{~mm}$ (20 to $365 \mathrm{~mm}$ ) for RCP8.5. For 1850 to $2300,90 \%$ of the MAGICC projections lie within 115 and $874 \mathrm{~mm}$ SLE (Levermann et al., 2014: 69 to $635 \mathrm{~mm}$ ) for RCP2.6, 209 and $1435 \mathrm{~mm}$ (119 to $1182 \mathrm{~mm}$ ) for RCP4.5, 282 and $1860 \mathrm{~mm}$ (161 to $1719 \mathrm{~mm}$ ) for RCP6.0, and 505 and $3173 \mathrm{~mm}$ (300 to $3535 \mathrm{~mm}$ ) for RCP8.5, respectively. The MAGICC Antarctic SID estimates, which are based on the physically more complex ice-shelf models only, mostly lie within the $90 \%$ range of Antarctic SID sea level contributions provided by Levermann et al. (2014).

In panel ( $\mathrm{t}$ ), we show SLE responses for the scenarioindependent land water SLE component. From 1900 to 2100, we include the net land water SLE contribution as presented in Fig. 3 of Wada et al. (2012), corrected by the $20 \%$ fraction of land water that does not reach the global ocean Wada et al. (2016). Post-2100, we assume a constant annual contribution based on the assumptions outlined in Sect. 2.5. 2100 estimates span a global sea level contribution of 39 to $77 \mathrm{~mm}$. The extended land water projections range from 156 to $261 \mathrm{~mm} \mathrm{SLE}$ for 2300.

With the individual SLR components calibrated, we can project total SLR as the combination of the individual SLE responses from each of the seven sea level components. Two 
different MAGICC setups are used to project global SLR until 2100 and 2300 based on the four RCP scenarios and their extensions. The ocean model update is not sufficient to make the MAGICC model fully CMIP5 consistent because other crucial climate system components such as the carbon cycle have not been updated yet. To overcome this issue, we constrain the MAGICC model with available CMIP5 globalmean tas time series. Together with the corresponding calibrated MAGICC ocean model parameter sets, we are able to create a CMIP5 environment that allows us to compare our 2100 global SLR projections to the latest IPCC estimates. Beyond 2100, the number of available CMIP5 simulations is much smaller, with only two 2300 model runs available for RCP6.0, for example. In order to also provide a sufficiently large number of model runs for 2300, we use 600 historically constrained parameter sets that have been derived using a probabilistic Metropolis-Hastings Markov chain Monte Carlo method (Meinshausen et al., 2009). This approach has been extended to also reflect carbon-cycle uncertainties (Friedlingstein et al., 2014) and the climate sensitivity range of the latest IPCC assessment (Flato et al., 2013; Rogelj et al., 2012, 2014). For this second setup, MAGICC is not forced to match CMIP5 global-mean tas, allowing us to provide consistent ensemble projections out to 2300 . For this ensemble, we randomly draw from the CMIP5 ocean model parameter sets and the calibration results for each sea level model component. Random samples are also sourced between the minimum and maximum realizations for the Greenland SID and LWS component as well as between the empirical basal melt sensitivities for the Antarctic SID contribution (Levermann et al., 2014). For consistency, we adopt the same ensemble size for the CMIP5 constrained MAGICC setup and randomly select the specific CMIP5 global-mean tas time series in addition to the other randomized parameter sets from the individual sea level components.

In Table 6, we show median SLR estimates for the 20812100 average relative to $1986-2005$ and $66 \%$ ranges for every individual component, with corresponding IPCC reference estimates and likely ranges. The individual MAGICC sea level contributions are in good agreement with the IPCC estimates. Figure 4 shows the full suite of MAGICC SLR projections for the RCP scenarios. The smaller panels (a) to (d) give 90 and $66 \%$ ranges as well as median responses for all RCP scenarios until 2100 based on the CMIP5-consistent setup. Additional bars are provided for the IPCC reference data and the probabilistic MAGICC setup, which is not constrained to CMIP5. For the CMIP5consistent MAGICC setup, 2100 median SLR is projected to be $0.45 \mathrm{~m}$ ( $66 \%$ range: $0.35 \mathrm{~m}$ to $0.56 \mathrm{~m}$ ) for RCP $2.6,0.55 \mathrm{~m}$ ( 0.45 to $0.67 \mathrm{~m})$ for RCP $4.5,0.56 \mathrm{~m}$ for $(0.46$ to $0.71 \mathrm{~m})$ for RCP6.0, and $0.79 \mathrm{~m}(0.65$ to $0.97 \mathrm{~m}$ ) for RCP8.5 (see also Table 7). All SLR projections are provided relative to the reference period 1986 to 2005. MAGICC SLR estimates for 2100 are generally higher than the IPCC projections. CMIP5consistent projections of average 2081 to 2100 SLR lie well within the IPCC range, with median estimates on average $0.02 \mathrm{~m}$ higher than the corresponding IPCC values (Church et al., 2013a). In panel (e), we provide 2300 SLR projections for the RCP extensions based on the probabilistic MAGICC setup, which is not constrained to CMIP5. For RCP2.6, the median SLR response is $1.02 \mathrm{~m}$ (66\% range: 0.80 to $1.35 \mathrm{~m}$ ). We project a median of $1.76 \mathrm{~m}$ (1.29 to $2.30 \mathrm{~m}$ ) for RCP4.5, $2.38 \mathrm{~m}$ ( 1.72 to $3.20 \mathrm{~m})$ for RCP6.0, and up to $4.73 \mathrm{~m}$ (3.41 to $6.82 \mathrm{~m}$ ) for RCP8.5 (see also Table 7). In Fig. A3, we provide MAGICC SLR hindcast results and three comparison datasets for the period 1900 to 2000. The MAGICC sea level model shows good agreement with the observational datasets based on Church et al. (2011) and Hay et al. (2015). The global 1900-2300 SLR responses are provided for all RCPs and each sea level component in the Appendix Figs. A4 to A7.

Figure 5 shows the global-mean tas responses based on the historically constrained, probabilistic MAGICC setup, which is used for the 2300 SLR projections. Each panel also includes the available CMIP5 global-mean tas time series; 2300 MAGICC median global-mean tas fall well within the available CMIP5 range for RCP4.5, RCP6.0, and RCP8.5. The MAGICC median global-mean tas response is at the lower end of 2300 CMIP5 temperatures for RCP2.6. For this scenario, the projected cooling over 22nd and 23rd centuries is consistent with previous MAGICC studies, e.g., Meinshausen et al. (2011c). The overall historically constrained, probabilistic MAGICC global-mean tas response for the 21st century is stronger than in the CMIP5 reference data for RCP4.5, RCP6.0, and RCP8.5 scenarios. This slightly steeper 21 st century global-mean tas slope is also reflected in the corresponding probabilistic MAGICC 2100 SLR estimates, given the strong air temperature dependence of the sea level model (see Fig. 4a to d).

\section{Discussion}

The MAGICC sea level model presented here synthesizes long-term sea level projections for seven sea level components and provides up-to-date and efficient representations of the individual SLR contributions, validated against processbased model results (see Fig. 3 and Sect. 2). Thermal expansion is calculated with an updated version of the MAGICC hemispheric upwelling-diffusion ocean model and an ocean-layer-specific thermal expansion parameterization by Lorbacher et al. (2015). We are therefore able to directly account for ocean heat uptake effects, which is an advantage over other contribution-based approaches that simply derive thermal expansion from global-mean air temperature changes (Mengel et al., 2016). The MAGICC ocean thermal expansion component is calibrated to be fully consistent with CMIP5. The glacier component parameterization accounts for both transient projections of glacier mass loss (Marzeion et al., 2012) and equilibrium glacier responses 
Table 6. The 2081-2100 median values and 66\% ranges for global SLR projections relative to 1986-2005 in meters, resolved by sea level components for the four RCP scenarios. Estimates are provided based on the CMIP5-consistent MAGICC setup. IPCC median projections and likely ranges are given as a reference.

\begin{tabular}{llrrrrr}
\hline \multicolumn{2}{c}{$2081-2100$} & RCP2.6 & RCP4.5 & RCP6.0 & RCP8.5 \\
\hline \multirow{2}{*}{ Total } & MAGICC & $0.41[0.32$ to 0.51$]$ & $0.49[0.41$ to 0.60$]$ & $0.49[0.40$ to 0.62$]$ & $0.67[0.55$ to 0.83$]$ \\
& IPCC & $0.40[0.26$ to 0.55$]$ & $0.47[0.32$ to 0.63$]$ & $0.48[0.33$ to 0.63$]$ & $0.63[0.45$ to 0.82$]$ \\
\hline \multirow{2}{*}{ Thermal Expansion $]$} & MAGICC & $0.12[0.08$ to 0.17$]$ & $0.16[0.12$ to 0.22$]$ & $0.17[0.12$ to 0.23$]$ & $0.26[0.19$ to 0.34$]$ \\
& IPCC & $0.14[0.10$ to 0.18$]$ & $0.19[0.14$ to 0.23$]$ & $0.19[0.15$ to 0.24$]$ & $0.27[0.21$ to 0.33$]$ \\
Glaciers & MAGICC & $0.11[0.09$ to 0.14$]$ & $0.13[0.11$ to 0.15$]$ & $0.13[0.10$ to 0.15$]$ & $0.15[0.13$ to 0.17$]$ \\
& IPCC & $0.10[0.04$ to 0.16$]$ & $0.12[0.06$ to 0.19$]$ & $0.12[0.06$ to 0.19$]$ & $0.16[0.09$ to 0.23$]$ \\
Greenland SMB & MAGICC & $0.03[0.01$ to 0.04$]$ & $0.04[0.02$ to 0.05$]$ & $0.03[0.02$ to 0.05$]$ & $0.06[0.04$ to 0.09$]$ \\
& IPCC & $0.03[0.01$ to 0.07$]$ & $0.04[0.01$ to 0.09$]$ & $0.04[0.01$ to 0.09$]$ & $0.07[0.03$ to 0.16$]$ \\
Greenland SID & MAGICC & $0.03[0.03$ to 0.04$]$ & $0.03[0.03$ to 0.04$]$ & $0.03[0.03$ to 0.04$]$ & $0.05[0.04$ to 0.06$]$ \\
& IPCC & $0.04[0.01$ to 0.06$]$ & $0.04[0.01$ to 0.06$]$ & $0.04[0.01$ to 0.06$]$ & $0.05[0.02$ to 0.07$]$ \\
Antarctica SMB & MAGICC & $-0.02[-0.03$ to -0.01$]$ & $-0.03[-0.03$ to 0.02$]$ & $-0.03[-0.04$ to -0.02$]$ & $-0.04[-0.05$ to -0.03$]$ \\
& IPCC & $-0.02[-0.04$ to -0.00$]$ & $-0.02[-0.05$ to -0.01$]$ & $-0.02[-0.05$ to -0.01$]$ & $-0.04[-0.07$ to -0.01$]$ \\
Antarctica SID & MAGICC & $0.07[0.04$ to 0.14$]$ & $0.08[0.06$ to 0.16$]$ & $0.08[0.05$ to 0.16$]$ & $0.11[0.06$ to 0.21$]$ \\
& IPCC & $0.07[-0.01$ to 0.16$]$ & $0.07[-0.01$ to 0.16$]$ & $0.07[-0.01$ to 0.16$]$ & $0.07[-0.01$ to 0.16$]$ \\
Land water storage & MAGICC & $0.06[0.05$ to 0.07$]$ & $0.06[0.05$ to 0.07$]$ & $0.06[0.05$ to 0.07$]$ & $0.06[0.05$ to 0.07$]$ \\
& IPCC & $0.04[-0.01$ to 0.09$]$ & $0.04[-0.01$ to 0.09$]$ & $0.04[-0.01$ to 0.09$]$ & $0.04[-0.01$ to 0.09$]$ \\
\hline
\end{tabular}
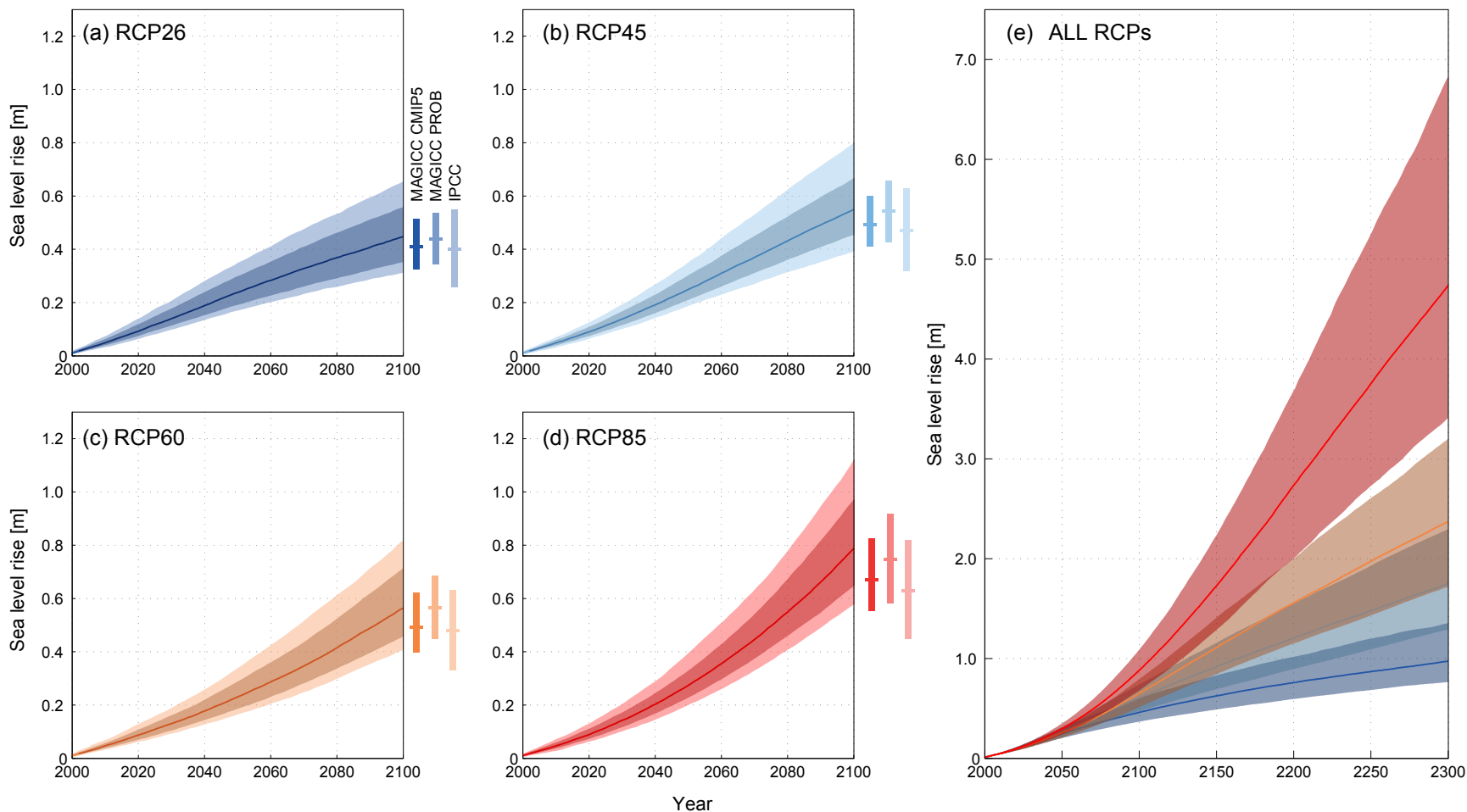

Figure 4. Global sea level projections until 2100 based on CMIP5 constrained MAGICC runs as anomalies relative to 1986-2005 in panels (a) to (d); $90 \%$ ensemble range in light colors, $66 \%$ ensemble range in darker colors, median as solid line. The 2081-2100 anomalies with respect to 1986-2005 as vertical bars for CMIP5 constrained MAGICC setup (MAGICC CMIP5), historically constrained probabilistic MAGICC setup (MAGICC PROB), and IPCC reference projections. The 2300 sea level projections in panel (e) are showing $66 \%$ ranges for all RCP extensions based on MAGICC PROB; median estimates as solid lines. 
Table 7. The 2100 and 2300 median values as well as $66 \%$ ranges for total global SLR projections relative to 1986-2005 based on the MAGICC CMIP5 and MAGICC PROB experimental designs. IPCC median projections and likely ranges are given as a reference.

\begin{tabular}{llrr}
\hline & & 2100 & 2300 \\
\hline \multirow{2}{*}{ RCP2.6 } & MAGICC CMIP5 & $0.45[0.35$ to 0.56$]$ & - \\
& MAGICC PROB & $0.48[0.37$ to 0.59$]$ & $1.02[0.80$ to 1.35$]$ \\
& IPCC & $0.44[0.28$ to 0.61$]$ & - \\
\hline \multirow{2}{*}{ RCP4.5 } & MAGICC CMIP5 & $0.55[0.45$ to 0.67$]$ & - \\
& MAGICC PROB & $0.61[0.48$ to 0.74$]$ & $1.76[1.29$ to 2.30$]$ \\
& IPCC & $0.53[0.36$ to 0.71$]$ & - \\
\hline \multirow{2}{*}{ RCP6.0 } & MAGICC CMIP5 & $0.56[0.46$ to 0.71$]$ & - \\
& MAGICC PROB & $0.65[0.52$ to 0.79$]$ & $2.38[1.72$ to 3.20] \\
& IPCC & $0.55[0.38$ to 0.73$]$ & - \\
\hline \multirow{2}{*}{ RCP8.5 } & MAGICC CMIP5 & $0.79[0.65$ to 0.97$]$ & - \\
& MAGICC PROB & $0.89[0.68$ to 1.09$]$ & $4.73[3.41$ to 6.82$]$ \\
& IPCC & $0.74[0.52$ to 0.98$]$ & - \\
\hline
\end{tabular}
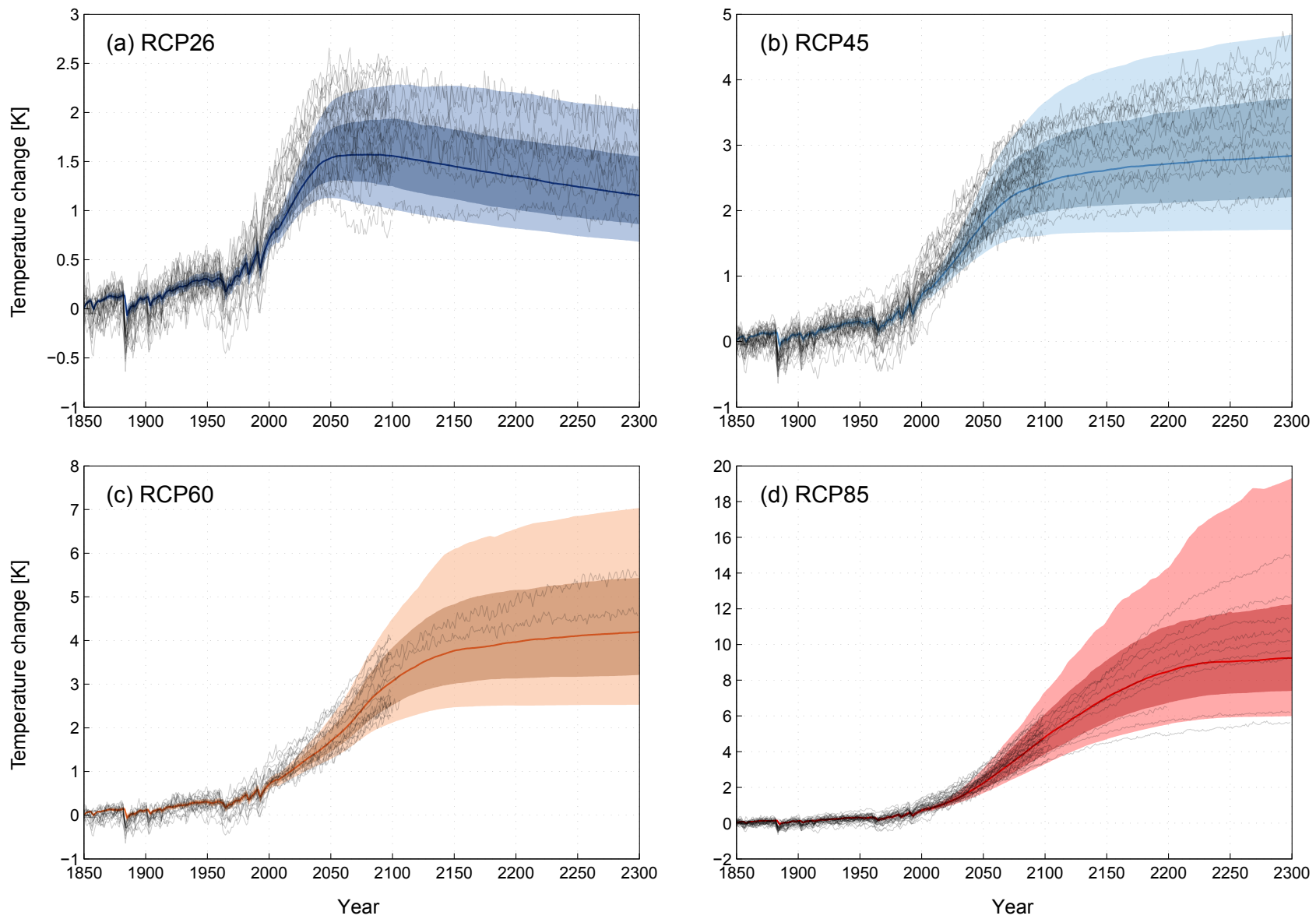

Figure 5. Global-mean tas projections until 2300 for all RCP extensions based on the historically constrained probabilistic MAGICC setup; $90 \%$ ensemble range in light colors, $66 \%$ ensemble range in darker colors, medians as solid lines. Available global CMIP5 tas reference time series are shown as thin black lines. All temperature projections are given relative to 1850 . 
based on Marzeion et al. (2014). The SMB and SID parameterizations for both ice sheets reflect available processbased reference data (Fettweis et al., 2013; Nick et al., 2013; Ligtenberg et al., 2013; Levermann et al., 2014). In addition, new process understanding has been included in the land water component (Wada et al., 2016). The full MAGICC model, including the sea level module, can be run in less than $1 \mathrm{~s}$ for 100 model years on a single core. This makes it an efficient platform to provide large ensembles of global sea level projections.

Projecting SLR beyond 2100 and providing physically consistent global estimates out to 2300 has been one of the key motivations for the development of the MAGICC sea level model. For five of the seven sea level components, the reference data used for calibrating the individual contributions extend beyond 2100. For thermal expansion, global glacier, and Antarctic SID contributions, the reference calibration period spans from 1850 to 2300. The remaining components are based on physically plausible assumptions, which allow us to also provide 2300 estimates, assuming that the calibrated parameterizations for each sea level component remain valid. Our sea level model transparently emulates and combines long-term sea level projections from process-based models. It is also in line with observed past total sea level change (see Fig. A3). The close reproduction of selected reference data (Figs. 3 and A3), together with the consistent translation of climate forcing into a SLR response within the MAGICC model, and the comprehensive representation of relevant processes (e.g., the thermal expansion contribution produced by the CMIP5-consistent MAGICC ocean model and the inclusion of the land water storage sea level component) make the MAGICC sea level model a powerful addition to the existing sea level emulators.

Both CMIP5 ocean and air temperatures serve as input for the presented sea level model. Other published sea level emulators only utilize air temperature projections, also provided by MAGICC, either based purely on available CMIP3 calibration results (Meinshausen et al., 2011a; Perrette et al., 2013) or an updated historically constrained probabilistic MAGICC setup that reflects the latest IPCC climate sensitivity estimates (Schleussner et al., 2016; Mengel et al., 2016). We here provide the first major step to making MAGICC fully CMIP5 consistent, with the ocean model now emulating 36 CMIP5 hemispheric potential ocean temperature and thermal expansion responses. However, other crucial elements of the MAGICC model, like the atmosphere and the carbon cycle, are not yet calibrated to CMIP5. When combining the CMIP5-calibrated ocean with the older atmosphere and carbon-cycle calibrations, the resulting 21 st century warming is slightly stronger than CMIP5 (see Fig. 5). To ensure a robust MAGICC sea level model, the individual components were either calibrated with prescribed CMIP5 temperatures, or with CMIP3-consistent time series whenever the reference data was based on the older generation of SRES and ENSEMBLES scenarios. The quality of the sea level model calibration is therefore not affected by the warmer MAGICC air temperature response. Our primary 2100 SLR projections are based on a MAGICC ensemble that is constrained by CMIP5 global-mean tas. These projections can therefore be directly compared to recent IPCC estimates. For our 2300 projections, we run MAGICC in the historically constrained, probabilistic setup described above. The resulting MAGICC air temperature responses mostly reflect the available CMIP5 reference data, although they show a shorter response time scale (see Fig. 5). These differences to CMIP5 translate into the corresponding SLR projections due to the strong air temperature dependence of the sea level model. Hence, the MAGICC sea level module will only be able to provide fully CMIP5-consistent SLR responses for 2300 once the remaining components of the MAGICC model have been updated.

Sea level emulators complement the comprehensive but computationally expensive, process-based sea level models due to their flexible and efficient design. They can be quickly adapted to, e.g., incorporate previously unknown uncertainties from newly quantified ice-sheet processes (Clark et al., 2016; DeConto and Pollard, 2016). Being directly coupled to MAGICC, our sea level model can also account for additional climate system response uncertainties and provide consistent projections for a wide range of climate change scenarios beyond the standard IPCC pathways. The latter aspects describe key strengths of the MAGICC sea level model and make it a useful tool to assess SLR for scenarios that are not covered by larger, more comprehensive models. The emulated MAGICC sea level projections reflect, independently, the reference responses of the calibration data for each individual sea level component, assuming that the implemented parameterizations fully capture the process-based simulations. Underlying model uncertainties differ substantially for the individual sea level components (Church et al., 2013b). In 2300, the three largest model response uncertainties captured by the MAGICC sea level model for RCP8.5 are the Greenland SMB component with $66 \%$ range estimates of 0.74 to $2.51 \mathrm{~m}$, the thermal expansion component with a $66 \%$ range of 1.07 to $2.65 \mathrm{~m}$, and the Antarctic SID component with 0.65 to $1.85 \mathrm{~m}$. Emulators, as presented here, can only cover the uncertainty ranges that are reflected in the emulated process-based models. Even though there have been substantial advances in process understanding over the last years, the physical representation of some sea level contributions remains incomplete. The Antarctic ice-sheet response, for example, could be subject to more rapid, nonlinear dynamics that is not captured by current process-based projections. Only recently, DeConto and Pollard (2016) have revised potential future Antarctic contributions to global sea level based on indicators from paleoclimatic archives. For RCP8.5, they suggest 2100 contributions of around $1 \mathrm{~m}$ from Antarctica alone, with 2300 contributions reaching up to around $10 \mathrm{~m}$. The MAGICC sea level model projections for the Antarctic SID contribution are based on Levermann et al. (2014) and 
only yield up to around $0.35 \mathrm{~m}$ in 2100 and $2.68 \mathrm{~m}$ in 2300 for the upper bound of the $90 \%$ range. As the more recent research suggests, these estimates may be too low, indicating that the Antarctic contribution to future SLR is subject to additional uncertainties. This illustrates the need to handle long-term SLR projections with care and to note the corresponding methodological caveats; in particular, those surrounding the representation of Antarctic ice-sheet changes.

The MAGICC sea level model assesses long-term global SLR trajectories by synthesizing available process-based projections for the individual sea level drivers and applying them to the available set of RCP scenarios and their extensions until 2300. The current version shows 2100 estimates that are well within the range of the latest IPCC assessment (see Fig. 4). The structure of the emulator makes the MAGICC sea level model a computationally much more efficient tool compared to the comprehensive and complex process-based models. The calibration routines for the individual components have been flexibly designed to allow for timely updates whenever new robust modeling results be- come available. The presented MAGICC sea level model, together with the MAGICC ocean model update, are new elements of MAGICC model version 6 (Meinshausen et al., 2011a). The implementation of the new sea level model initiates the development of MAGICC model version 7 to comprehensively emulate CMIP5 projections. The full potential of the MAGICC sea level model will be unlocked once this MAGICC model upgrade has been completed.

Code and data availability. The Fortran code of the MAGICC sea level model together with its documentation is available at https: //doi.org/10.5281/zenodo.572395 (Nauels et al., 2017a). Supporting data and configuration information to reproduce results of the MAGICC sea level model are provided at https://doi.org/10.5281/ zenodo.572398 (Nauels et al., 2017b). CMIP5 model output is freely available from the PCMDI database: http://cmip-pcmdi.llnl. gov/. Additional reference datasets for the individual sea level components can be requested from the authors of the corresponding studies. 


\section{Appendix A}

Additional information on MAGICC sea level model calibration parameters, MAGICC ocean model calibration results, MAGICC SLR hindcast quality, and component-wise MAGICC SLR projections for 1900-2300.

Table A1. List of variables and free parameters used for the individual MAGICC sea level component calibrations.

\begin{tabular}{|c|c|c|}
\hline Climate variables & Unit & Description \\
\hline tas & $\mathrm{K}$ & surface air temperature \\
\hline thetao & $\mathrm{K}$ & potential ocean temperature \\
\hline zostoga & $\mathrm{mm}$ & thermal expansion \\
\hline \multicolumn{3}{|c|}{ MAGICC ocean parameters } \\
\hline$K_{z}$ & $\mathrm{~cm}^{2} \mathrm{~s}^{-1}$ & vertical thermal diffusivity \\
\hline$\frac{\mathrm{d} \tilde{K}_{z \text { top }}}{\mathrm{d} T}$ & $\mathrm{~cm}^{2} \mathrm{~s}^{-1} \mathrm{~K}^{-1}$ & sensitivity to global-mean tas at the mixed-layer boundary \\
\hline$\eta$ & $\mathrm{K}$ & sea-ice adjustment offset \\
\hline$\gamma$ & $\mathrm{K}^{-1}$ & sea-ice adjustment factor \\
\hline$w_{0}$ & $\mathrm{~m} \mathrm{yr}^{-1}$ & initial upwelling velocity \\
\hline$\beta$ & & ratio of changes in temperature of entraining waters to polar sinking waters \\
\hline$\frac{\Delta w_{t}}{w_{t}}$ & & ratio of variable to fixed upwelling \\
\hline $\begin{array}{l}T_{w_{t}} \\
\phi\end{array}$ & $\mathrm{K}$ & $\begin{array}{l}\text { threshold temperatures for constant upwelling rates } \\
\text { global thermal expansion scaling }\end{array}$ \\
\hline \multicolumn{3}{|l|}{ Glacier parameters } \\
\hline$\kappa$ & $\mathrm{K}^{-1}$ & glacier sensitivity \\
\hline$v$ & & temperature sensitivity exponent \\
\hline \multicolumn{3}{|c|}{ Greenland SMB parameters } \\
\hline$v$ & $\mathrm{~mm} \mathrm{~K}^{-1}$ & temperature sensitivity \\
\hline$\chi$ & & relative magnitude of linear and nonlinear terms \\
\hline$\hat{\varphi}$ & & temperature sensitivity exponent \\
\hline \multicolumn{3}{|c|}{ Greenland SID parameters } \\
\hline$\varrho$ & & discharge sensitivity \\
\hline$\epsilon$ & $\mathrm{K}^{-1}$ & temperature sensitivity \\
\hline GIS $_{\max }^{\text {outlet }}$ & $\mathrm{mm}$ & maximum Greenland outlet glacier volume \\
\hline \multicolumn{3}{|c|}{ Antarctic SMB parameters } \\
\hline$\xi$ & $\mathrm{mm} \mathrm{K}^{-1}$ & temperature sensitivity \\
\hline$\rho$ & & relative magnitude of linear and nonlinear terms \\
\hline$\sigma$ & & temperature sensitivity exponent \\
\hline
\end{tabular}




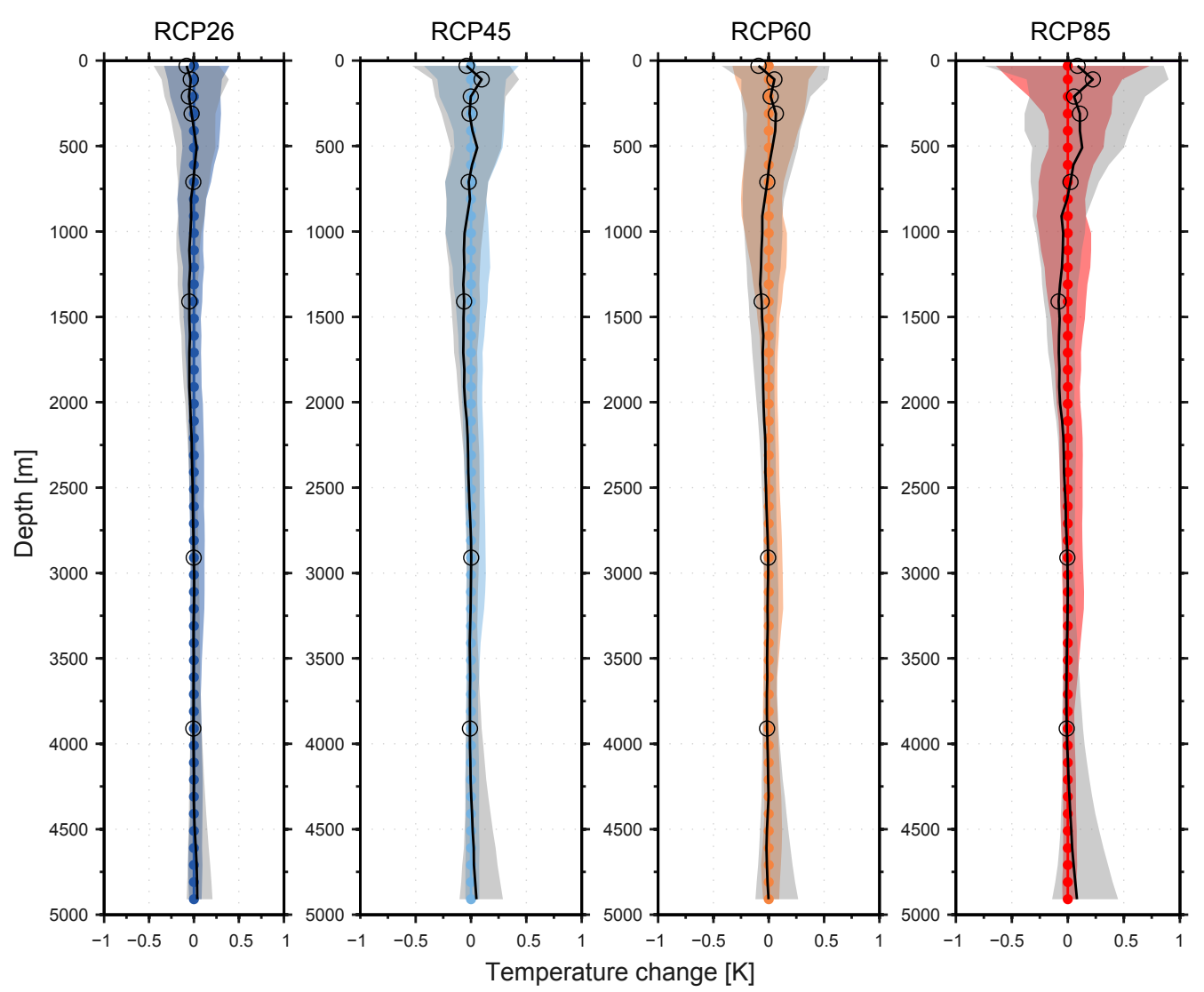

Figure A1. Potential ocean temperature residuals for calibrated MAGICC and reference CMIP5 ocean warming under RCP2.6, RCP4.5, RCP6.0, and RCP8.5 scenarios. Residuals are given with respect to the median CMIP5 2081-2100 to 1986-2005 anomalies for every MAGICC ocean layer. CMIP5 reference median and $90 \%$ range are shown in color, with circles indicating the individual MAGICC ocean layers. Calibrated MAGICC $90 \%$ model range and median residuals are provided as gray shadings and black lines with open circles indicating the selected layers for the ocean calibration. 

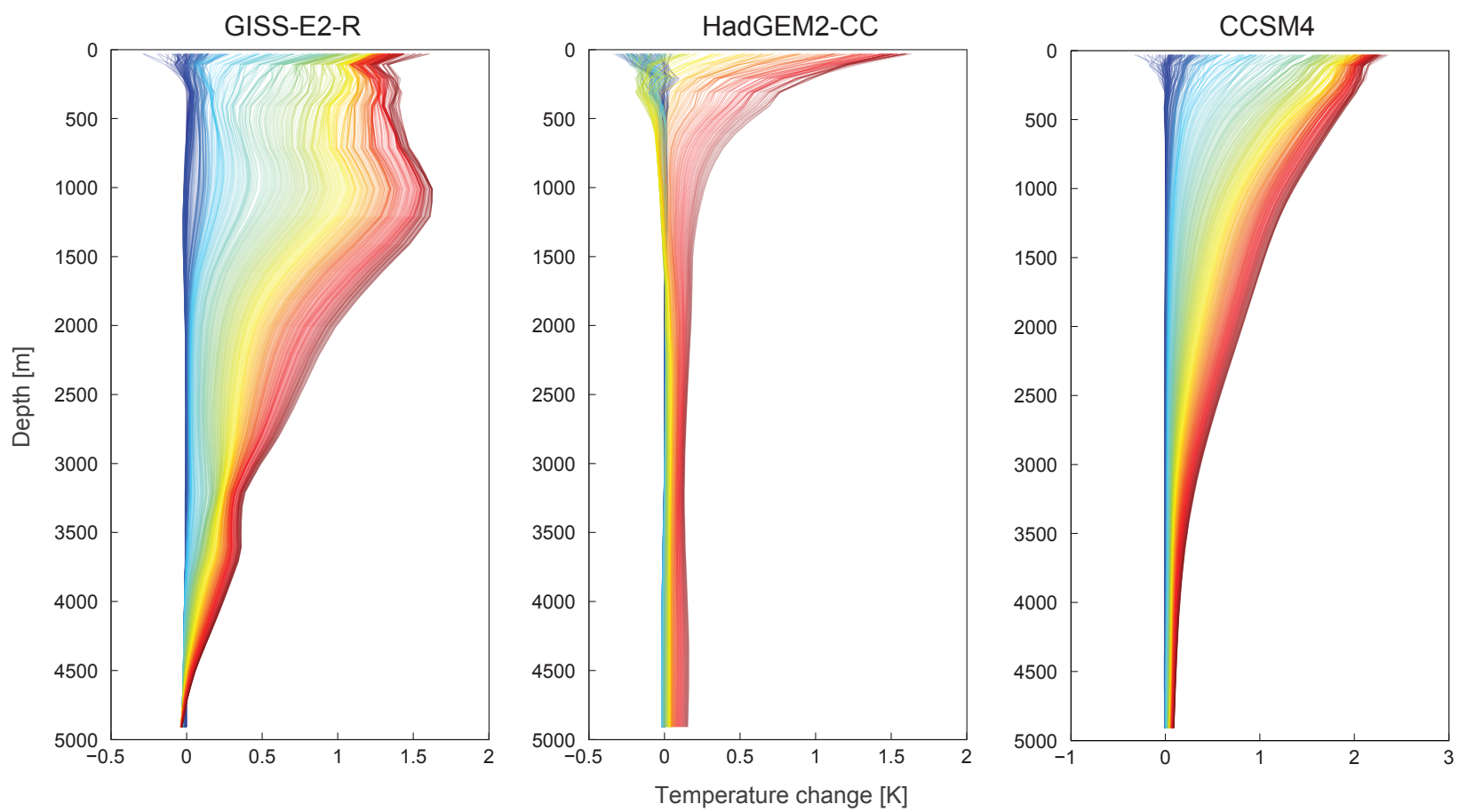

Figure A2. Annual RCP4.5 ocean warming anomalies for the CMIP5 models GISS-E2-R (1850-2300), HadGEM2-CC (1850-2100), and CCSM (1850-2300), relative to 1850 and globally averaged. Annual potential ocean temperature anomaly profiles are shown as dark blue in 1850 via green and yellow to red for the last year of the reference data.

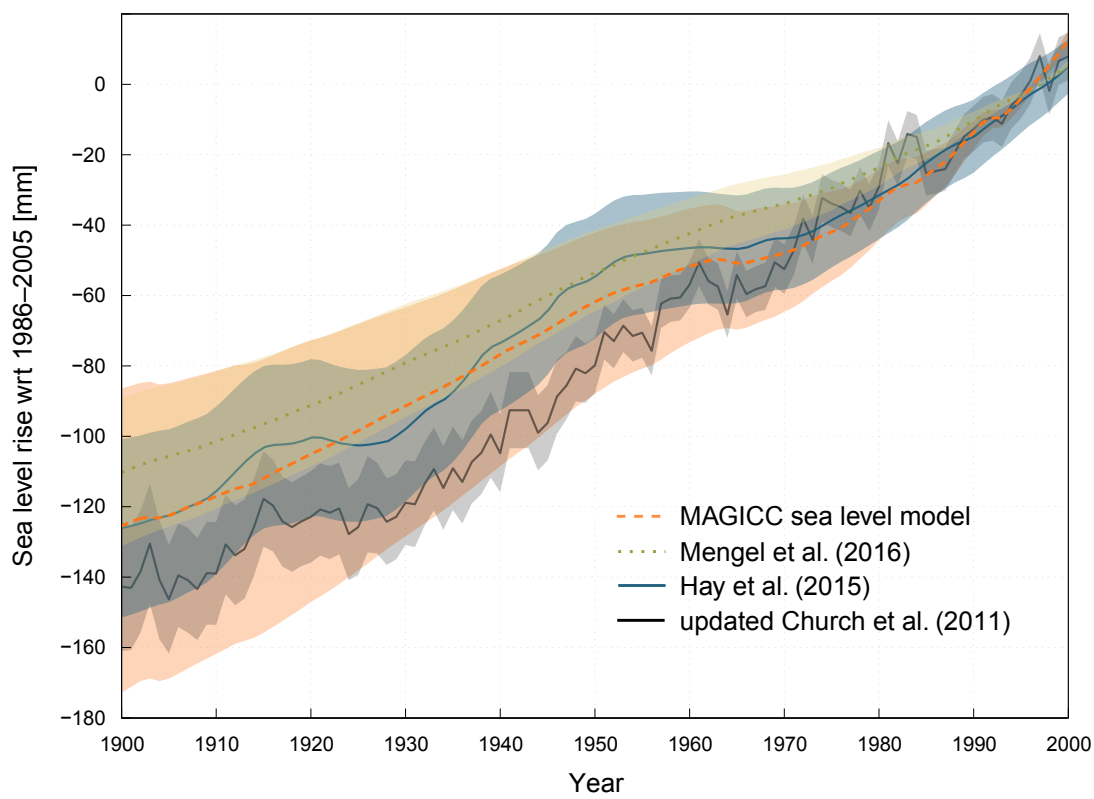

Figure A3. Historical modeled and observed SLR from 1900 to 2000, relative to the 1986-2005 mean. Median and $90 \%$ uncertainty ranges are shown for the MAGICC hindcast (orange) and results from Mengel et al. (2016) (khaki), with observed sea level time series and respective uncertainties based on Hay et al. (2015) (blue) and the updated Church et al. (2011) datasets (gray). 

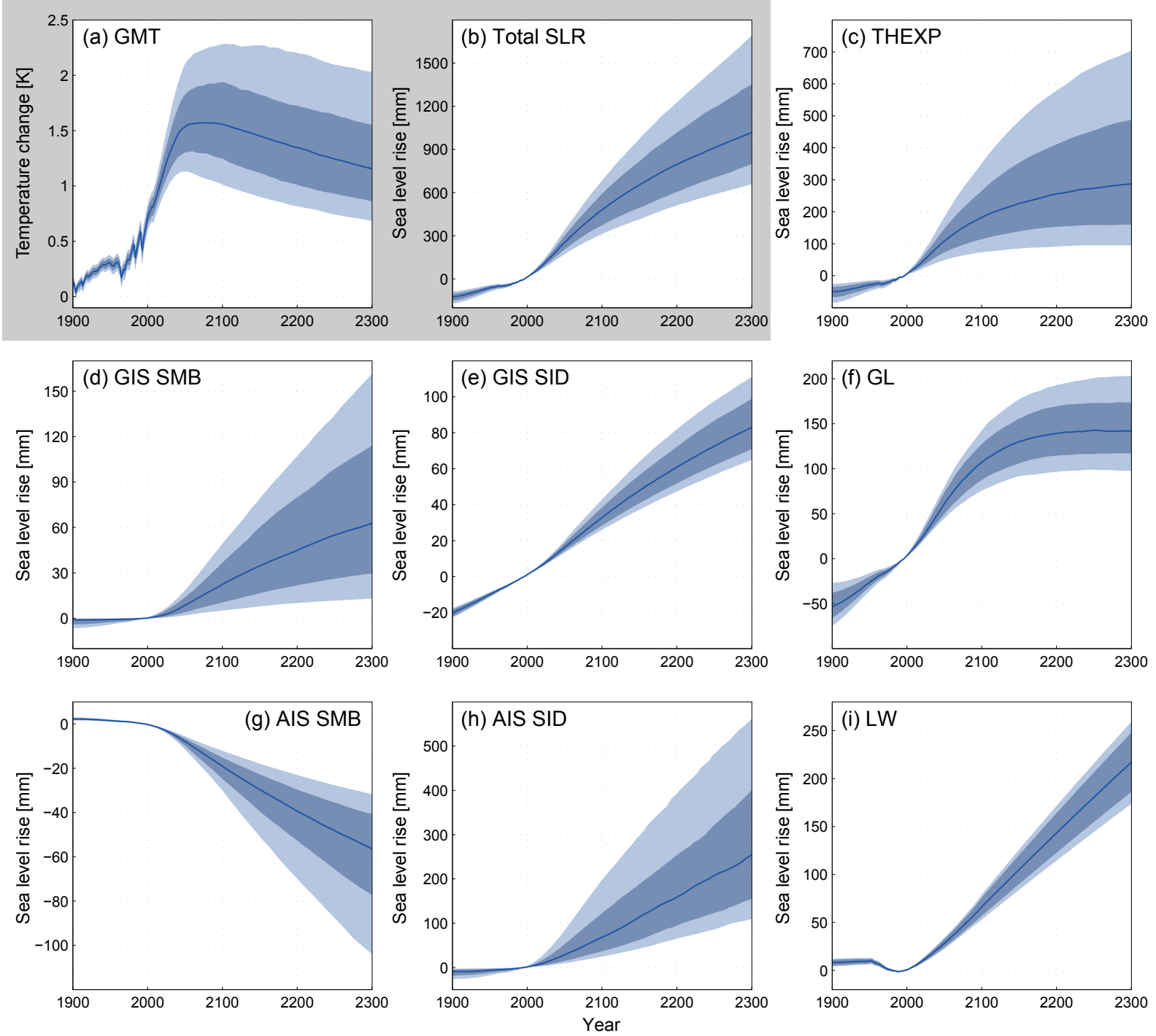

Figure A4. The 1900-2300 SLR projections resolved by the individual MAGICC sea level components for RCP2.6 in millimeters. We show median estimates, $66 \%$ ranges in darker shading, and $90 \%$ ranges in lighter shading for MAGICC GMT output relative to pre-industrial in panel (a), total SLR in panel (b), thermal expansion (THEXP) in panel (c), Greenland ice-sheet (GIS) SMB and SID in panels (d) and (e), global glacier (GL) in panel (f), Antarctic ice sheet (AIS) SMB and SID in panels (g) and (h), and land water LW in panel (i). All sea level contributions are provided relative to 1986-2005. 

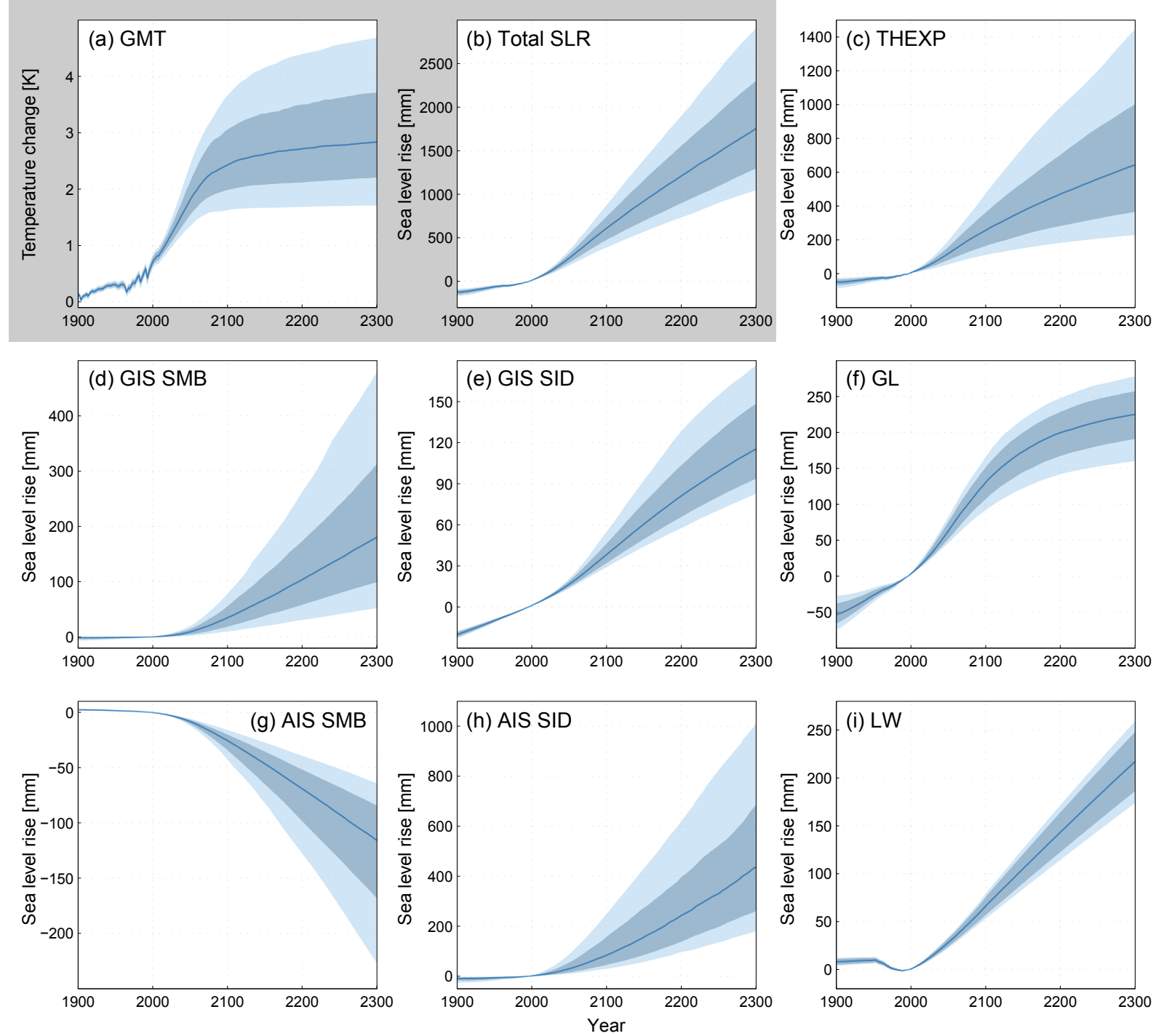

Figure A5. The 1900-2300 SLR projections resolved by the individual MAGICC sea level components for RCP4.5 in millimeters. We show median estimates, $66 \%$ ranges in darker shading, and $90 \%$ ranges in lighter shading for MAGICC GMT output relative to pre-industrial in panel (a), total SLR in panel (b), thermal expansion (THEXP) in panel (c), Greenland ice-sheet (GIS) SMB and SID in panels (d) and (e), global glacier (GL) in panel (f), Antarctic ice sheet (AIS) SMB and SID in panels (g) and (h), and land water LW in panel (i). All sea level contributions are provided relative to 1986-2005. 

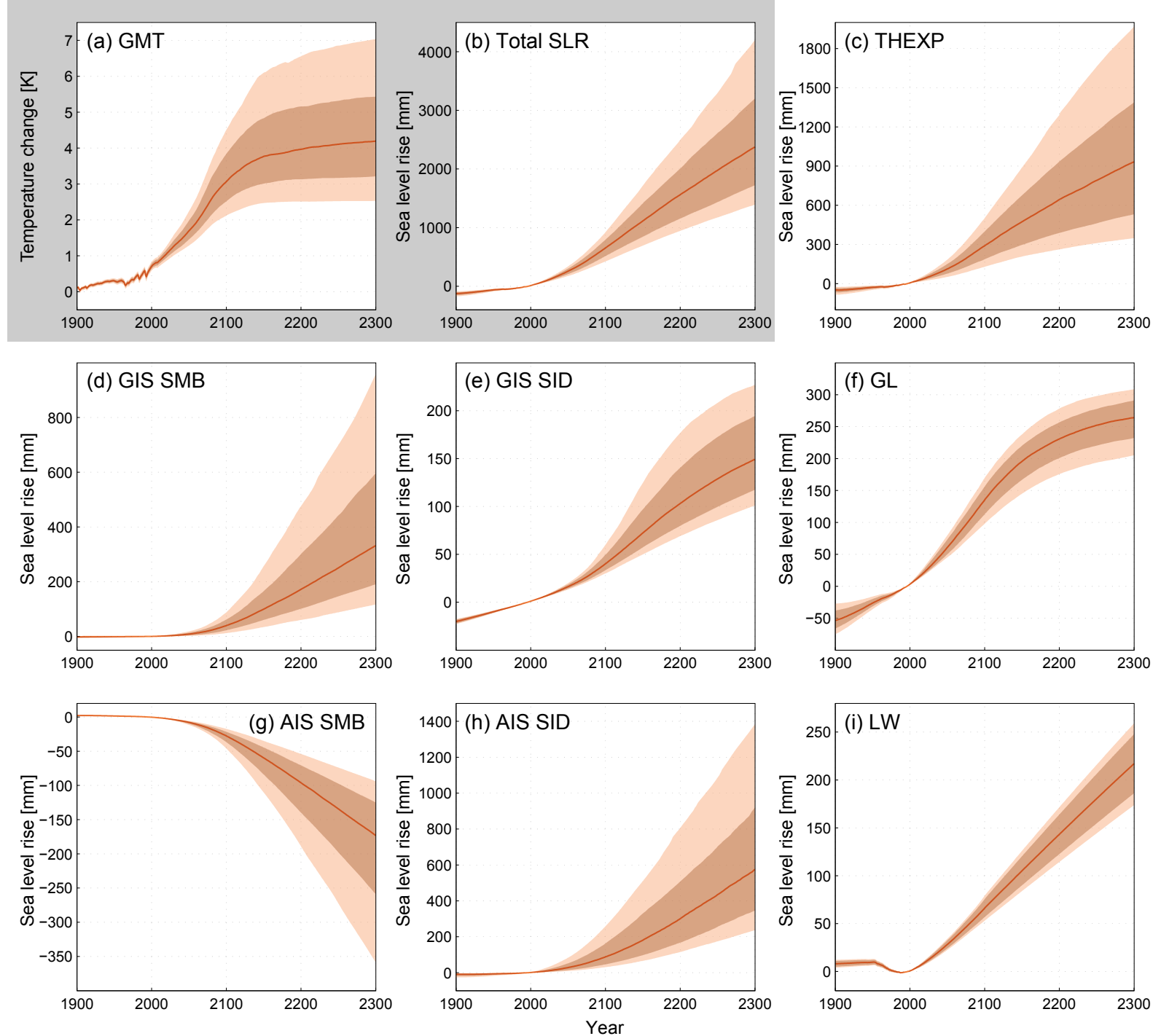

Figure A6. The 1900-2300 SLR projections resolved by the individual MAGICC sea level components for RCP6.0 in millimeters. We show median estimates, $66 \%$ ranges in darker shading, and $90 \%$ ranges in lighter shading for MAGICC GMT output relative to pre-industrial in panel (a), total SLR in panel (b), thermal expansion (THEXP) in panel (c), Greenland ice-sheet (GIS) SMB and SID in panels (d) and (e), global glacier (GL) in panel (f), Antarctic ice sheet (AIS) SMB and SID in panels (g) and (h), and land water LW in panel (i). All sea level contributions are provided relative to 1986-2005. 

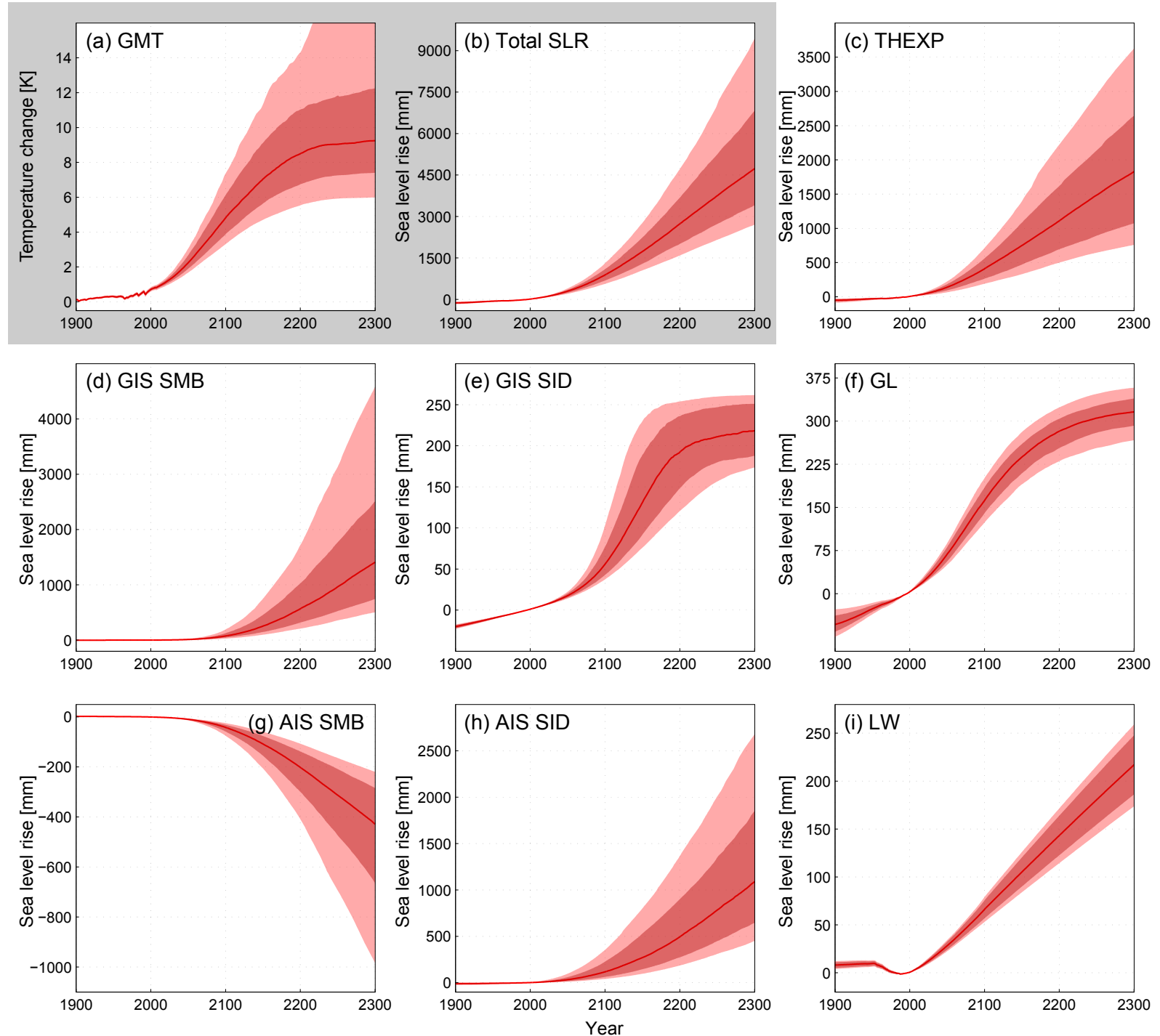

Figure A7. The 1900-2300 SLR projections resolved by the individual MAGICC sea level components for RCP8.5 in millimeters. We show median estimates, $66 \%$ ranges in darker shading, and $90 \%$ ranges in lighter shading for MAGICC GMT output relative to pre-industrial in panel (a), total SLR in panel (b), thermal expansion (THEXP) in panel (c), Greenland ice-sheet (GIS) SMB and SID in panels (d) and (e), global glacier (GL) in panel (f), Antarctic ice sheet (AIS) SMB and SID in panels (g) and (h), and land water LW in panel (i). All sea level contributions are provided relative to 1986-2005. 
Author contributions. A. Nauels developed and calibrated the sea level model with support from M. Meinshausen, M. Mengel, and K. Lorbacher. A. Nauels conducted the experiments and drafted the manuscript. All authors contributed to the text.

Competing interests. The authors declare that they have no conflict of interest.

Acknowledgements. We acknowledge the World Climate Research Programme's Working Group on Coupled Modeling, which is responsible for CMIP, and we thank the climate modeling groups for producing and making available their model output (CMIP5 models used in the present study are listed in Table 1 of this paper; see also http: //cmip-pcmdi.llnl.gov/cmip5/docs/CMIP5_modeling_groups.pdf).

For CMIP the U.S. Department of Energy's Program for Climate Model Diagnosis and Intercomparison provides coordinating support and led development of software infrastructure in partnership with the Global Organization for Earth System Science Portals. We would especially like to thank B. Marzeion, X. Fettweis, F. Nick, S. Ligtenberg, A. Levermann, and Y. Wada for providing the calibration data used in this study. The authors would also like to acknowledge C. Hay and J. Church and the CSIRO for making available their GMSL reconstruction/reanalysis datasets. M. Meinshausen receives the Australian Research Council (ARC) Future Fellowship Grant FT130100809. T. M. L. Wigley is supported by the Australian Research Council under Discovery Grant DP130103261.

Edited by: D. Ham

Reviewed by: two anonymous referees

\section{References}

Bamber, J. L., Riva, R. E. M., Vermeersen, B. L. A., and LeBrocq, A. M.: Reassessment of the Potential Sea-Level Rise from a Collapse of the West Antarctic Ice Sheet, Science, 324, 901-903, 2009.

Bamber, J. L., Griggs, J. A., Hurkmans, R. T. W. L., Dowdeswell, J. A., Gogineni, S. P., Howat, I., Mouginot, J., Paden, J., Palmer, S., Rignot, E., and Steinhage, D.: A new bed elevation dataset for Greenland, The Cryosphere, 7, 499-510, https://doi.org/10.5194/tc-7-499-2013, 2013.

Bengtsson, L., Koumoutsaris, S., and Hodges, K.: Large-Scale Surface Mass Balance of Ice Sheets from a Comprehensive Atmospheric Model, Surv. Geophys., 32, 459-474, 2011.

Bindschadler, R. A., Nowicki, S., Abe-Ouchi, A., Aschwanden, A., Choi, H., Fastook, J., Granzow, G., Greve, R., Gutowski, G., Herzfeld, U., Jackson, C., Johnson, J., Khroulev, C., Levermann, A., Lipscomb, W. H., Martin, M. A., Morlighem, M., Parizek, B. R., Pollard, D., Price, S. F., Ren, D., Saito, F., Sato, T., Seddik, H., Seroussi, H., Takahashi, K., Walker, R., and Wang, W. L.: Icesheet model sensitivities to environmental forcing and their use in projecting future sea level (the SeaRISE project), J. Glaciol., 59, 195-224, 2013.
Church, J. A. and White, N. J.: Sea-Level Rise from the Late 19th to the Early 21st Century, Surv. Geophys., 32, 585-602, 2011.

Church, J. A., Gregory, J. M., White, N. J., Platten, S. M., and Mitrovica, J. X.: Understanding and Projecting Sea Level Change, Oceanography, 24, 130-143, 2011.

Church, J. A., Clark, P., Cazenave, A., Gregory, J., Jevrejeva, S., Levermann, A., Merrifield, M., Milne, G., Nerem, R., Nunn, P., Payne, A., Pfeffer, W., Stammer, D., and Unnikrishnan, A.: Climate Change 2013: The Physical Science Basis. Contribution of Working Group I to the Fifth Assessment Report of the Intergovernmental Panel on Climate Change, chap. 13. Sea Level Change, Cambridge University Press, Cambridge, UK and New York, NY, USA, 2013a.

Church, J. A., Monselesan, D., Gregory, J. M., and Marzeion, B.: Evaluating the ability of process based models to project sea-level change, Environ. Res. Lett., 8, 014051, https://doi.org/10.1088/1748-9326/8/1/014051, 2013b.

Clark, P. U., Shakun, J. D., Marcott, S. A., Mix, A. C., Eby, M., Kulp, S., Levermann, A., Milne, G. A., Pfister, P. L., Santer, B. D., Schrag, D. P., Solomon, S., Stocker, T. F., Strauss, B. H., Weaver, A. J., Winkelmann, R., Archer, D., Bard, E., Goldner, A., Lambeck, K., Pierrehumbert, R. T., and Plattner, G.-K.: Consequences of twenty-first-century policy for multi-millennial climate and sea-level change, Nature Clim. Change, 6, 360-369, 2016.

DeConto, R. M. and Pollard, D.: Contribution of Antarctica to past and future sea-level rise, Nature, 531, 591-597, 2016.

de Graaf, I., van Beek, L., Wada, Y., and Bierkens, M.: Dynamic attribution of global water demand to surface water and groundwater resources: Effects of abstractions and return flows on river discharges, Adv. Water Resour., 64, 21-33, 2014.

Favier, L., Durand, G., Cornford, S. L., Gudmundsson, G. H., Gagliardini, O., Gillet-Chaulet, F., Zwinger, T., Payne, A. J., and Le Brocq, A. M.: Retreat of Pine Island Glacier controlled by marine ice-sheet instability, Nature Clim. Change, 4, 117-121, 2014.

Fettweis, X., Tedesco, M., van den Broeke, M., and Ettema, J.: Melting trends over the Greenland ice sheet (1958-2009) from spaceborne microwave data and regional climate models, The Cryosphere, 5, 359-375, https://doi.org/10.5194/tc-5-359-2011, 2011.

Fettweis, X., Franco, B., Tedesco, M., van Angelen, J. H., Lenaerts, J. T. M., van den Broeke, M. R., and Gallée, H.: Estimating the Greenland ice sheet surface mass balance contribution to future sea level rise using the regional atmospheric climate model MAR, The Cryosphere, 7, 469-489, https://doi.org/10.5194/tc7-469-2013, 2013.

Flato, G., Marotzke, J., Abiodun, B., Braconnot, P., Chou, S., Collins, W., Cox, P., Driouech, F., Emori, S., Eyring, V., Forest, C., Gleckler, P., Guilyardi, E., Jakobs, C., Kattsov, V., Reason, C., and Rummukainen, M.: Evaluation of Climate Models, in: Climate Change 2013: The Physical Science Basis. Contribution of Working Group I to the Fifth Assessment Report of the Intergovernmental Panel on Climate Change, chap. 9, edited by: Stocker, T. F., Qin, D., Plattner, G.-K., Tignor, M., Allen, S. K., Boschung, J., Nauels, A., Xia, Y., Bex, V., and Midgley, P. M., Cambridge University Press, Cambridge, UK and New York, NY, USA, 2013. 
Friedlingstein, P., Andrew, R. M., Rogelj, J., Peters, G. P., Canadell, J. G., Knutti, R., Luderer, G., Raupach, M. R., Schaeffer, M., van Vuuren, D. P., and Le Quere, C.: Persistent growth of $\mathrm{CO}_{2}$ emissions and implications for reaching climate targets, Nat. Geosci., 7, 709-715, 2014.

Frieler, K., Meinshausen, M., Mengel, M., Braun, N., and Hare, W.: A Scaling Approach to Probabilistic Assessment of Regional Climate Change, J. Climate, 25, 3117-3144, 2012.

Frieler, K., Mengel, M., and Levermann, A.: Delaying future sealevel rise by storing water in Antarctica, Earth Syst. Dynam., 7, 203-210, https://doi.org/10.5194/esd-7-203-2016, 2016.

Fürst, J. J., Goelzer, H., and Huybrechts, P.: Ice-dynamic projections of the Greenland ice sheet in response to atmospheric and oceanic warming, The Cryosphere, 9, 1039-1062, https://doi.org/10.5194/tc-9-1039-2015, 2015.

Gleeson, T., Befus, K. M., Jasechko, S., Luijendijk, E., and Cardenas, M. B.: The global volume and distribution of modern groundwater, Nat. Geosci., 9, 161-167, 2015.

Goelzer, H., Huybrechts, P., Raper, S. C. B., Loutre, M.-F., Goosse, H., and Fichefet, T.: Millennial total sea-level commitments projected with the Earth system model of intermediate complexity LOVECLIM, Environ. Res. Lett., 7, 045401, https://doi.org/10.1088/1748-9326/7/4/045401, 2012.

Goelzer, H., Huybrechts, P., Furst, J. J., Nick, F. M., Andersen, M. L., Edwards, T. L., Fettweis, X., Payne, A. J., and Shannon, S.: Sensitivity of Greenland ice sheet projections to model formulations, J. Glaciol., 59, 733-749, 2013.

Gornitz, V., Lebedeff, S., and Hansen, J.: Global Sea Level Trend in the Past Century, Science, 215, 1611-1614, 1982.

Gregory, J. and Huybrechts, P.: Ice-sheet contributions to future sealevel change, Philos. T. R. Soc. A, 364, 1709-1732, 2006.

Gregory, J. M., Bi, D., Collier, M. A., Dix, M. R., Hirst, A. C., Hu, A., Huber, M., Knutti, R., Marsland, S. J., Meinshausen, M., Rashid, H. A., Rotstayn, L. D., Schurer, A., and Church, J. A.: Climate models without preindustrial volcanic forcing underestimate historical ocean thermal expansion, Geophys. Res. Lett., 40, 1600-1604, 2013a.

Gregory, J. M., White, N. J., Church, J. A., Bierkens, M. F. P., Box, J. E., van den Broeke, M. R., Cogley, J. G., Fettweis, X., Hanna, E., Huybrechts, P., Konikow, L. F., Leclercq, P. W., Marzeion, B., Oerlemans, J., Tamisiea, M. E., Wada, Y., Wake, L. M., and van de Wal, R. S. W.: Twentieth-Century Global-Mean Sea Level Rise: Is the Whole Greater than the Sum of the Parts?, J. Climate, 26, 4476-4499, 2013b.

Griffies, S. M. and Greatbatch, R. J.: Physical processes that impact the evolution of global mean sea level in ocean climate models, Ocean Model., 51, 37-72, 2012.

Griffies, S. M., Yin, J., Durack, P. J., Goddard, P., Bates, S. C., Behrens, E., Bentsen, M., Bi, D., Biastoch, A., Böning, C. W., Bozec, A., Chassignet, E., Danabasoglu, G., Danilov, S., Domingues, C. M., Drange, H., Farneti, R., Fernandez, E., Greatbatch, R. J., Holland, D. M., Ilicak, M., Large, W. G., Lorbacher, K., Lu, J., Marsland, S. J., Mishra, A., George Nurser, A. J., Salas y Mélia, D., Palter, J. B., Samuels, B. L., Schröter, J., Schwarzkopf, F. U., Sidorenko, D., Treguier, A. M., Tseng, Y.-h., Tsujino, H., Uotila, P., Valcke, S., Voldoire, A., Wang, Q., Winton, M., and Zhang, X.: An assessment of global and regional sea level for years 1993-2007 in a suite of interannual CORE-II simulations, Ocean Model., 78, 35-89, 2014.
Grinsted, A.: An estimate of global glacier volume, The Cryosphere, 7, 141-151, https://doi.org/10.5194/tc-7-141-2013, 2013.

Gupta, A. S., Jourdain, N. C., Brown, J. N., and Monselesan, D.: Climate Drift in the CMIP5 Models, J. Climate, 26, 8597-8615, 2013.

Hargreaves, J. and Annan, J.: Assimilation of paleo-data in a simple Earth system model, Clim. Dynam., 19, 371-381, 2002.

Hay, C. C., Morrow, E., Kopp, R. E., and Mitrovica, J. X.: Probabilistic reanalysis of twentieth-century sea-level rise, Nature, 517, 481-484, 2015.

Holland, P. R., Jenkins, A., and Holland, D. M.: The response of ice shelf basal melting to variations in ocean temperature, J. Climate, 21, 2558-2572, 2008.

Horton, B. P., Rahmstorf, S., Engelhart, S. E., and Kemp, A. C.: Expert assessment of sea-level rise by AD 2100 and AD 2300, Quaternary Sci. Rev., 84, 1-6, 2014.

Huybrechts, P., Goelzer, H., Janssens, I., Driesschaert, E., Fichefet, T., Goosse, H., and Loutre, M. F.: Response of the Greenland and Antarctic Ice Sheets to Multi-Millennial Greenhouse Warming in the Earth System Model of Intermediate Complexity LOVECLIM, Surv. Geophys., 32, 397-416, 2011.

Jacobs, S. S., Helmer, H. H., Doake, C. S. M., Jenkins, A., and Frolich, R. M.: Melting of Ice Shelves and the Mass Balance of Antarctica, J. Glaciol., 38, 375-387, 1992.

Jenkins, A.: A one-dimensional model of ice shelf-ocean interaction, J. Geophys. Res.-Oceans, 96, 20671-20677, 1991.

Jevrejeva, S., Moore, J. C., and Grinsted, A.: How will sea level respond to changes in natural and anthropogenic forcings by 2100?, Geophys. Res. Lett., 37, L07703, https://doi.org/10.1029/2010GL042947, 2010.

Johns, T. C., Gregory, J. M., Ingram, W. J., Johnson, C. E., Jones, A., Lowe, J. A., Mitchell, J. F. B., Roberts, D. L., Sexton, D. M. H., Stevenson, D. S., Tett, S. F. B., and Woodage, M. J.: Anthropogenic climate change for 1860 to 2100 simulated with the HadCM3 model under updated emissions scenarios, Clim. Dynam., 20, 583-612, 2003.

Joughin, I., Alley, R. B., and Holland, D. M.: Ice-Sheet Response to Oceanic Forcing, Science, 338, 1172-1176, 2012.

Joughin, I., Smith, B. E., and Medley, B.: Marine Ice Sheet Collapse Potentially Under Way for the Thwaites Glacier Basin, West Antarctica, Science, 344, 735-738, 2014.

Khan, S. A., Aschwanden, A., Bjørk, A. A., Wahr, J., Kjeldsen, K. K., and Kjær, K. H.: Greenland ice sheet mass balance: a review, Rep. Prog. Phys., 78, 046801, https://doi.org/10.1088/0034-4885/78/4/046801, 2015.

Konikow, L. F.: Contribution of global groundwater depletion since 1900 to sea-level rise, Geophys. Res. Lett., 38, L17401, https://doi.org/10.1029/2011GL048604, 2011.

Kopp, R. E., Horton, R. M., Little, C. M., Mitrovica, J. X., Oppenheimer, M., Rasmussen, D. J., Strauss, B. H., and Tebaldi, C.: Probabilistic 21st and 22nd century sea-level projections at a global network of tide-gauge sites, Earth's Future, 2, 383-406, 2014.

Kopp, R. E., Kemp, A. C., Bittermann, K., Horton, B. P., Donnelly, J. P., Gehrels, W. R., Hay, C. C., Mitrovica, J. X., Morrow, E. D., and Rahmstorf, S.: Temperature-driven global sea-level variability in the Common Era, P. Natl. Acad. Sci. USA, 113, 1434 1441, 2016. 
Krinner, G., Magand, O., Simmonds, I., Genthon, C., and Dufresne, J. L.: Simulated Antarctic precipitation and surface mass balance at the end of the twentieth and twenty-first centuries, Clim. Dynam., 28, 215-230, 2006.

Kuhlbrodt, T. and Gregory, J. M.: Ocean heat uptake and its consequences for the magnitude of sea level rise and climate change, Geophys. Res. Lett., 39, L18608, https://doi.org/10.1029/2012GL052952, 2012.

Lagarias, J., Reeds, J., Wright, M., and Wright, P.: Convergence Properties of the Nelder-Mead Simplex Method in Low Dimensions, SIAM J. Optim., 9, 112-147, 1998.

Leclercq, P. W., Oerlemans, J., and Cogley, J. G.: Estimating the Glacier Contribution to Sea-Level Rise for the Period 18002005, Surv. Geophys., 32, 519-535, 2011.

Lenaerts, J. T. M., van den Broeke, M. R., van de Berg, W. J., van Meijgaard, E., and Kuipers Munneke, P.: A new, high-resolution surface mass balance map of Antarctica (1979-2010) based on regional atmospheric climate modeling, Geophys. Res. Lett., 39, L04501, https://doi.org/10.1029/2011GL050713, 2012.

Levermann, A., Clark, P. U., Marzeion, B., Milne, G. A., Pollard, D., Radic, V., and Robinson, A.: The multimillennial sea-level commitment of global warming, P. Natl. Acad. Sci. USA, 110, 13745-13750, https://doi.org/10.1073/pnas.1219414110, 2013.

Levermann, A., Winkelmann, R., Nowicki, S., Fastook, J. L., Frieler, K., Greve, R., Hellmer, H. H., Martin, M. A., Meinshausen, M., Mengel, M., Payne, A. J., Pollard, D., Sato, T., Timmermann, R., Wang, W. L., and Bindschadler, R. A.: Projecting Antarctic ice discharge using response functions from SeaRISE ice-sheet models, Earth Syst. Dynam., 5, 271-293, https://doi.org/10.5194/esd-5-271-2014, 2014.

Ligtenberg, S. R. M., van de Berg, W. J., van den Broeke, M. R., Rae, J. G. L., and van Meijgaard, E.: Future surface mass balance of the Antarctic ice sheet and its influence on sea level change, simulated by a regional atmospheric climate model, Clim. Dynam., 41, 867-884, 2013.

Lorbacher, K., Nauels, A., and Meinshausen, M.: Complementing thermosteric sea level rise estimates, Geosci. Model Dev., 8, 2723-2734, https://doi.org/10.5194/gmd-8-2723-2015, 2015.

Martin, M. A., Winkelmann, R., Haseloff, M., Albrecht, T., Bueler, E., Khroulev, C., and Levermann, A.: The Potsdam Parallel Ice Sheet Model (PISM-PIK) - Part 2: Dynamic equilibrium simulation of the Antarctic ice sheet, The Cryosphere, 5, 727-740, https://doi.org/10.5194/tc-5-727-2011, 2011.

Marzeion, B., Jarosch, A. H., and Hofer, M.: Past and future sealevel change from the surface mass balance of glaciers, The Cryosphere, 6, 1295-1322, https://doi.org/10.5194/tc-6-12952012, 2012.

Marzeion, B., Cogley, J. G., Richter, K., and Parkes, D.: Attribution of global glacier mass loss to anthropogenic and natural causes, Science, 345, 919-921, 2014.

Meinshausen, M., Meinshausen, N., Hare, W., Raper, S. C. B., Frieler, K., Knutti, R., Frame, D. J., and Allen, M. R.: Greenhouse-gas emission targets for limiting global warming to 2 degrees C, Nature, 458, 1158-1162, 2009.

Meinshausen, M., Raper, S. C. B., and Wigley, T. M. L.: Emulating coupled atmosphere-ocean and carbon cycle models with a simpler model, MAGICC6 - Part 1: Model description and calibration, Atmos. Chem. Phys., 11, 1417-1456, https://doi.org/10.5194/acp-11-1417-2011, 2011a.
Meinshausen, M., Wigley, T. M. L., and Raper, S. C. B.: Emulating atmosphere-ocean and carbon cycle models with a simpler model, MAGICC6 - Part 2: Applications, Atmos. Chem. Phys., 11, 1457-1471, https://doi.org/10.5194/acp-111457-2011, 2011b.

Meinshausen, M., Smith, S. J., Calvin, K., Daniel, J. S., Kainuma, M. L. T., Lamarque, J. F., Matsumoto, K., Montzka, S. A., Raper, S. C. B., Riahi, K., Thomson, A., Velders, G. J. M., and van Vuuren, D. P. P.: The RCP greenhouse gas concentrations and their extensions from 1765 to 2300, Climatic Change, 109, 213-241, 2011c.

Mengel, M., Levermann, A., Frieler, K., Robinson, A., Marzeion, B., and Winkelmann, R.: Future sea level rise constrained by observations and long-term commitment, P. Natl. Acad. Sci. USA, 113, 2597-2602, 2016.

Moss, R. H., Edmonds, J. A., Hibbard, K. A., Manning, M. R., Rose, S. K., van Vuuren, D. P., Carter, T. R., Emori, S., Kainuma, M., Kram, T., Meehl, G. A., Mitchell, J. F. B., Nakicenovic, N., Riahi, K., Smith, S. J., Stouffer, R. J., Thomson, A. M., Weyant, J. P., and Wilbanks, T. J.: The next generation of scenarios for climate change research and assessment, Nature, 463, 747-756, 2010.

Nauels, A., Meinshausen, M., Mengel, M., Lorbacher, K., and Wigley, T. M. L.: Source code for "Synthesizing long-term sea level rise projections - the MAGICC sea level model v2.0", https://doi.org/10.5281/zenodo.572395, 2017a.

Nauels, A., Meinshausen, M., Mengel, M., Lorbacher, K., and Wigley, T. M. L.: Supporting data for "Synthesizing long-term sea level rise projections - the MAGICC sea level model v2.0", https://doi.org/10.5281/zenodo.572398, 2017b.

Nelder, J. A. and Mead, R.: A simplex method for function minimization, Comput. J., 7, 308-313, 1965.

Nicholls, R. J. and Cazenave, A.: Sea-Level Rise and Its Impact on Coastal Zones, Science, 328, 1517-1520, 2010.

Nick, F. M., Vieli, A., Howat, I. M., and Joughin, I.: Large-scale changes in Greenland outlet glacier dynamics triggered at the terminus, Nat. Geosci., 2, 110-114, 2009.

Nick, F. M., Vieli, A., Andersen, M. L., Joughin, I., Payne, A., Edwards, T. L., Pattyn, F., and van de Wal, R. S. W.: Future sea-level rise from Greenlands main outlet glaciers in a warming climate, Nature, 497, 235-238, 2013.

Orlic, M. and Pasaric, Z.: Semi-empirical versus process-based sea-level projections for the twenty-first century, Nature Clim. Change, 3, 735-738, 2013.

Pattyn, F., Schoof, C., Perichon, L., Hindmarsh, R. C. A., Bueler, E., de Fleurian, B., Durand, G., Gagliardini, O., Gladstone, R., Goldberg, D., Gudmundsson, G. H., Huybrechts, P., Lee, V., Nick, F. M., Payne, A. J., Pollard, D., Rybak, O., Saito, F., and Vieli, A.: Results of the Marine Ice Sheet Model Intercomparison Project, MISMIP, The Cryosphere, 6, 573-588, https://doi.org/10.5194/tc-6-573-2012, 2012.

Payne, A. J., Holland, P. R., Shepherd, A. P., Rutt, I. C., Jenkins, A., and Joughin, I.: Numerical modeling of ocean-ice interactions under Pine Island Bay's ice shelf, J. Geophys. Res.-Oceans, 112, C10019, https://doi.org/10.1029/2006JC003733, 2007.

Perrette, M., Landerer, F., Riva, R., Frieler, K., and Meinshausen, M.: A scaling approach to project regional sea level rise and its uncertainties, Earth Syst. Dynam., 4, 11-29, https://doi.org/10.5194/esd-4-11-2013, 2013. 
Pfeffer, W. T., Arendt, A. A., Bliss, A., Bolch, T., Cogley, J. G., Gardner, A. S., Hagen, J.-O., Hock, R., Kaser, G., Kienholz, C., Miles, E. S., Moholdt, G., Mölg, N., Paul, F., Radi, Valentina, Rastner, P., Raup, B. H., Rich, J., and Sharp, M. J.: The Randolph Glacier Inventory: a globally complete inventory of glaciers, J. Glaciol., 60, 537-552, 2014.

Pokhrel, Y. N., Hanasaki, N., Yeh, P. J. F., Yamada, T. J., Kanae, S., and Oki, T.: Model estimates of sea-level change due to anthropogenic impacts on terrestrial water storage, Nat. Geosci., 5, 389-392, 2012.

Pollard, D. and DeConto, R. M.: Description of a hybrid ice sheetshelf model, and application to Antarctica, Geosci. Model Dev., 5, 1273-1295, https://doi.org/10.5194/gmd-5-1273-2012, 2012.

Price, S. F., Payne, A. J., Howat, I. M., and Smith, B. E.: Committed sea-level rise for the next century from Greenland ice sheet dynamics during the past decade, P. Natl. Acad. Sci. USA, 108, 8978-8983, https://doi.org/10.1073/pnas.1017313108, 2011.

Rae, J. G. L., Aðalgeirsdóttir, G., Edwards, T. L., Fettweis, X., Gregory, J. M., Hewitt, H. T., Lowe, J. A., Lucas-Picher, P., Mottram, R. H., Payne, A. J., Ridley, J. K., Shannon, S. R., van de Berg, W. J., van de Wal, R. S. W., and van den Broeke, M. R.: Greenland ice sheet surface mass balance: evaluating simulations and making projections with regional climate models, The Cryosphere, 6, 1275-1294, https://doi.org/10.5194/tc-6-1275-2012, 2012.

Rahmstorf, S.: A semi-empirical approach to projecting future sealevel rise, Science, 315, 368-370, 2007.

Raper, S. C. B., Gregory, J. M., and Osborn, T. J.: Use of an upwelling-diffusion energy balance climate model to simulate and diagnose AOGCM results, Clim. Dynam., 17, 601-613, 2001.

Rignot, E., Koppes, M., and Velicogna, I.: Rapid submarine melting of the calving faces of West Greenland glaciers, Nat. Geosci., 3, 187-191, 2010.

Rignot, E., Mouginot, J., Morlighem, M., Seroussi, H., and Scheuchl, B.: Widespread, rapid grounding line retreat of Pine Island, Thwaites, Smith, and Kohler glaciers, West Antarctica, from 1992 to 2011, Geophys. Res. Lett., 41, 3502-3509, 2014.

Robinson, A., Calov, R., and Ganopolski, A.: Multistability and critical thresholds of the Greenland ice sheet, Nature Clim. Change, 2, 429-432, 2012.

Roeckner, E., Baeuml, G., Bonaventura, L., Brokopf, R., Esch, M., Giorgetta, M., Hagemann, S., Kirchner, I., Kornblueh, L., Manzini, E., Rhodin, A., Schlese, U., Schulzweida, U., and Tompkins, A.: The atmospheric general circulation model ECHAM 5. PART I: Model description, Report No. 349, Tech. rep., Max-Planck-Institut fuer Meteorologie, Hamburg, Germany, 2003.

Rogelj, J., Meinshausen, M., and Knutti, R.: Global warming under old and new scenarios using IPCC climate sensitivity range estimates, Nature Clim. Change, 2, 248-253, 2012.

Rogelj, J., Meinshausen, M., Sedláček, J., and Knutti, R.: Implications of potentially lower climate sensitivity on climate projections and policy, Environ. Res. Lett., 9, 031003, https://doi.org/10.1088/1748-9326/9/3/031003, 2014.

Sato, T. and Greve, R.: Sensitivity experiments for the Antarctic ice sheet with varied sub-ice-shelf melting rates, Ann. Glaciol., 53, 221-228, 2012.
Schaeffer, M., Hare, W., Rahmstorf, S., and Vermeer, M.: Longterm sea-level rise implied by 1.5 degrees $\mathrm{C}$ and 2 degrees $\mathrm{C}$ warming levels, Nature Clim. Change, 2, 867-870, 2012.

Schleussner, C.-F., Lissner, T. K., Fischer, E. M., Wohland, J., Perrette, M., Golly, A., Rogelj, J., Childers, K., Schewe, J., Frieler, K., Mengel, M., Hare, W., and Schaeffer, M.: Differential climate impacts for policy-relevant limits to global warming: the case of $1.5^{\circ} \mathrm{C}$ and $2{ }^{\circ} \mathrm{C}$, Earth Syst. Dynam., 7, 327-351, https://doi.org/10.5194/esd-7-327-2016, 2016.

Storch, H., Zorita, E., and Gonzalez-Rouco, J. F.: Relationship between global mean sea-level and global mean temperature in a climate simulation of the past millennium, Ocean Dynam., 58, 227-236, 2008.

Taylor, K. E., Stouffer, R. J., and Meehl, G. A.: An Overview of CMIP5 and the Experiment Design, B. Am. Meteorol. Soc., 93, 485-498, 2012.

van Beek, L. P. H., Wada, Y., and Bierkens, M. F. P.: Global monthly water stress: 1. Water balance and water availability, Water Resour. Res., 47, W07517, https://doi.org/10.1029/2010WR009791, 2011.

van den Broeke, M., Bamber, J., Ettema, J., Rignot, E., Schrama, E., van de Berg, W. J., van Meijgaard, E., Velicogna, I., and Wouters, B.: Partitioning Recent Greenland Mass Loss, Science, 326, 984 986, 2009.

Vaughan, D. G., Comiso, J., Allison, I., Carrasco, J., Kaser, G., Kwok, R., Mote, P., Murray, T., Paul, F., Ren, D., Rignot, E., Solomina, O., Steffen, K., Zhang, N.: Observations: Cryosphere, in: Climate Change 2013: The Physical Science Basis. Contribution of Working Group I to the Fifth Assessment Report of the Intergovernmental Panel on Climate Change, chap. 4, edited by: Stocker, T. F., Qin, D., Plattner, G.-K., Tignor, M., Allen, S. K., Boschung, J., Nauels, A., Xia, Y., Bex, V., and Midgley, P. M., Cambridge University Press, Cambridge, UK and New York, NY, USA, 2013.

Vermeer, M. and Rahmstorf, S.: Global sea level linked to global temperature, P. Natl. Acad. Sci. USA, 106, 21527-21532, 2009.

Vizcaíno, M., Mikolajewicz, U., Jungclaus, J., and Schurgers, G.: Climate modification by future ice sheet changes and consequences for ice sheet mass balance, Clim. Dynam., 34, 301-324, 2010.

Vizcaino, M., Mikolajewicz, U., Ziemen, F., Rodehacke, C. B., Greve, R., and van den Broeke, M. R.: Coupled simulations of Greenland Ice Sheet and climate change up to A.D. 2300, Geophys. Res. Lett., 42, 3927-3935, 2015.

Wada, Y.: Modeling Groundwater Depletion at Regional and Global Scales: Present State and Future Prospects, Surv. Geophys., 37, 419-451, https://doi.org/10.1007/s10712-015-9347-x, 2016.

Wada, Y., van Beek, L. P. H., Sperna Weiland, F. C., Chao, B. F., Wu, Y.-H., and Bierkens, M. F. P.: Past and future contribution of global groundwater depletion to sea-level rise, Geophys. Res. Lett., 39, L09402, https://doi.org/10.1029/2012GL051230, 2012.

Wada, Y., Lo, M.-H., Yeh, P. J. F., Reager, J. T., Famiglietti, J. S., Wu, R.-J., and Tseng, Y.-H.: Fate of water pumped from underground and contributions to sea-level rise, Nature Clim. Change, 6, 777-780, 2016.

Wigley, T. M. L.: Global-mean temperature and sea level consequences of greenhouse gas concentration stabilization, Geophys Res. Lett., 22, 45-48, 1995. 
Wigley, T. M. L. and Raper, S. C. B.: Thermal expansion of sea water associated with global warming, Nature, 330, 127-131, 1987.

Wigley, T. M. L. and Raper, S. C. B.: Implications for climate and sea level of revised IPCC emissions scenarios, Nature, 357, 293 300, 1992.

Wigley, T. M. L. and Raper, S. C. B.: Interpretation of High Projections for Global-Mean Warming, Science, 293, 451-454, 2001.

Wigley, T. M. L. and Raper, S. C. B.: Extended scenarios for glacier melt due to anthropogenic forcing, Geophys. Res. Lett., 32, L05704, https://doi.org/10.1029/2004GL021238, 2005.

Wigley, T. M. L., Clarke, L. E., Edmonds, J. A., Jacoby, H. D., Paltsev, S., Pitcher, H., Reilly, J. M., Richels, R., Sarofim, M. C., and Smith, S. J.: Uncertainties in climate stabilization, Climatic Change, 97, 85-121, 2009.
Winkelmann, R. and Levermann, A.: Linear response functions to project contributions to future sea level, Clim. Dynam., 40, 2579-2588, 2012.

Winkelmann, R., Martin, M. A., Haseloff, M., Albrecht, T., Bueler, E., Khroulev, C., and Levermann, A.: The Potsdam Parallel Ice Sheet Model (PISM-PIK) - Part 1: Model description, The Cryosphere, 5, 715-726, https://doi.org/10.5194/tc-5-715-2011, 2011.

Wong, T. E., Bakker, A., Ruckert, K., Applegate, P., Slangen, A., and Keller, K.: BRICK v0.1, a simple, accessible, and transparent model framework for climate and regional sea-level projections, Geosci. Model Dev. Discuss., https://doi.org/10.5194/gmd-2016303, in review, 2017. 